
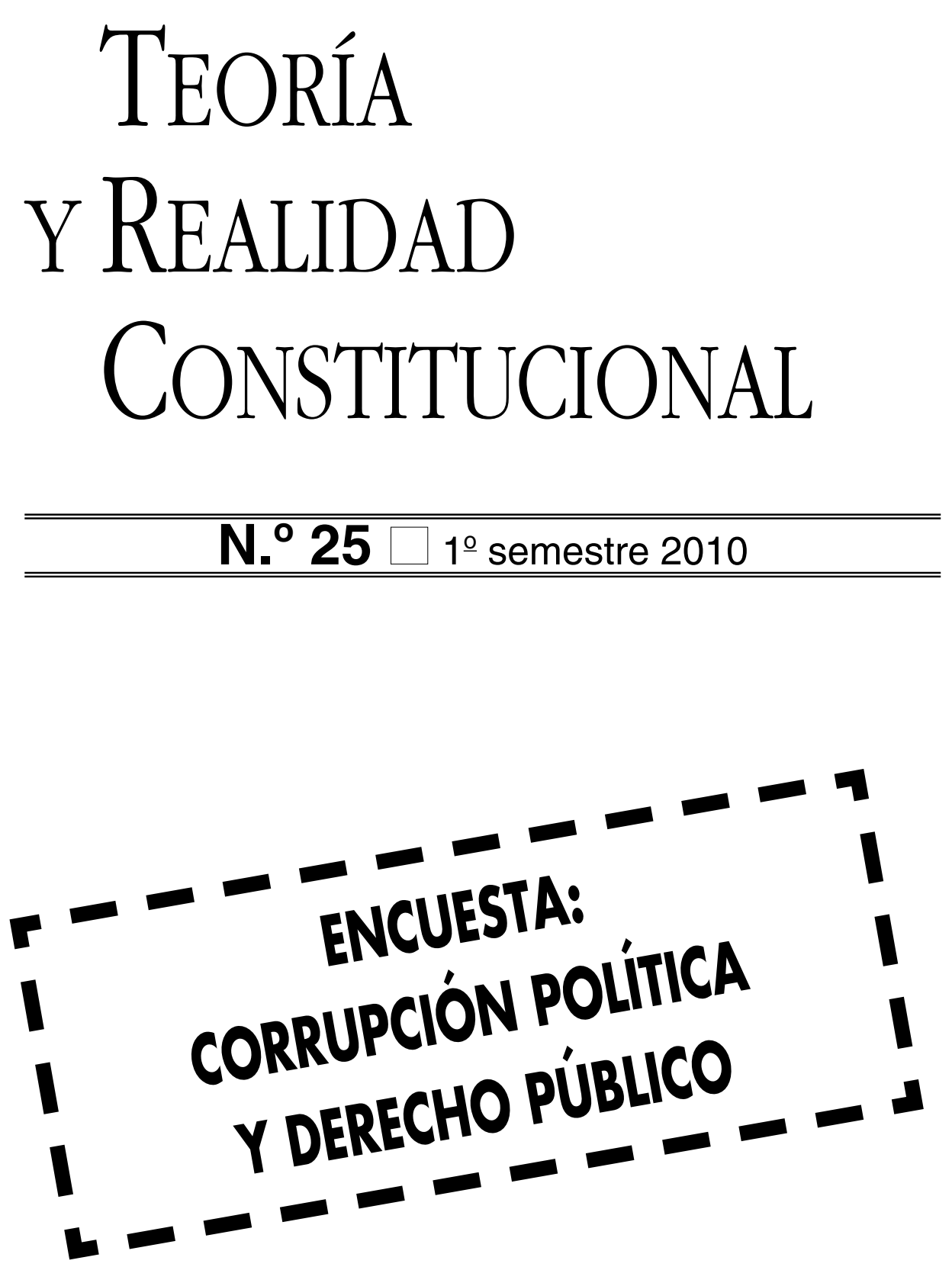


\title{
CORRUPCIÓN POLÍTICA: UN ANÁLISIS DESDE LA TEORÍA Y LA REALIDAD CONSTITUCIONAL
}

\author{
RAFAEL BUSTOS GISBERT \\ Profesor Titular de Derecho Constitucional \\ Universidad de Salamanca
}

SUMARIO

I. Complejidad y moralismo: Dos peligros previos en el análisis jurídico de la corrupción.

II. Dificultades en el estudio jurídico constitucional de la corrupción política como consecuencia de la concurrencia de puntos de vista heterogéneos.

III. Un concepto útil para el análisis jurídico: El modelo principal-agente.

IV. Buscando reglas de conducta en la teoría constitucional: La noción de Trust.

V. Las reglas de conducta de los políticos desde la realidad constitucional: Un análisis de la evolución en el Reino Unido.

VI. Reflexiones desde la realidad constitucional española.

\section{COMPLEJIDAD Y MORALISMO: DOS PELIGROS PREVIOS EN EL ANÁLISIS JURÍDICO DE LA CORRUPCIÓN}

El estudio de la corrupción política resulta complejo. En especial si se pretende un análisis fundamentalmente conceptual. Complejidad que, desde luego, no se deriva de la ausencia de estudios sobre el tema. Si bien tenían razón Laporta o Nieto ${ }^{1}$ cuando denunciaban la ausencia de estudios españoles

1 F.J. LAPORTA y S. ALVAREZ, en la presentación de ambos del libro por ellos editado, La corrupción política, Alianza Madrid, 1997, págs. 13-14 y A. NIETO, quien lamentaba la alta pro- 
sobre la cuestión a mediados de la década de los 90, lo cierto es que no sólo esta laguna ha sido cubierta ${ }^{2}$ por los investigadores españoles, o afincados en España, sino que en la literatura comparada, la citada década, a decir de Heidenheimer y Johnston, es sin lugar a dudas la más prolífica en trabajos dedicados a la cuestión ${ }^{3}$. Sin embargo, tal profusión de estudios no ha provocado una mayor claridad conceptual. Más bien al contrario, señala Sajó ${ }^{4}$ : $\mathrm{La}$ Corrupción es un concepto bien establecido al menos en un sentido: todos sabemos que los expertos nunca se pondrán de acuerdo en una definición concretan. Incluso es posible que esta proliferación de trabajos haya generado un cierto e indeseable expansionismo del concepto ${ }^{5}$ incluyendo cada vez más comportamientos o conductas susceptibles de ser incluidos bajo la etiqueta de actos de corrupción política.

Destacamos este entusiasmo intelectual en torno a la corrupción política y el carácter expansivo del concepto en los últimos 20 años en la introducción de este trabajo para anunciar desde el comienzo la intención de evitar algunas derivaciones de esos estudios y de esa expansión. Nos referimos a la tendencia, denunciada por Sajó o por Jacobs", a un exceso de "moralismo" o "buenismo" detectable en muchos de los estudios modernos sobre la materia ${ }^{7}$. Los estudios teóricos no deben ser apologías o excusas para cruzadas morales que, en definitiva, acabarían teniendo como principal víctima a la propia democracia en cuanto, por una parte, generarían expectativas imposibles de cumplir en torno al comportamiento de los gobernantes o políticos, por

ducción editorial sobre corrupción desde la perspectiva informativa frente a la poca producción analítica, en Corrupción en la España Democrática, Ariel, Madrid, 1997, pág. 11.

2 Sin ánimo de exhaustividad y desde perspectiva conceptuales y disciplinares diferentes véanse los trabajos monográficos del propio NIETO citado en la nota anterior; J.F. MALEM SEÑA (Globalización, comercio internacional y corrupción, Barcelona, 2000 y La corrupción, Aspectos éticos, económicos y jurídicos, Barcelona, 2000 ), o M. VILLORIA MENDIETA (La corrupción política, Síntesis, Madrid, 2006) y un conjunto de trabajos colectivos de alta calidad como los de LAPORTA y ALVAREZ ya citado, P. ANDRÉS IBÁÑEZ, Corrupción y Estado de Derecho. El papel de la jurisdicción, Trotta, Madrid, 1996; V. Zapatero (coord), La corrupción, México DF, 2007; o N. RODRÍGUEZ GARCÍA y E. FABIÁN CAPARRÓS (La corrupción: aspectos jurídicos y económicos, Ratio Legis, Salamanca, 2000 y La corrupción en un mundo globalizado: análisis interdisciplinar, Ratio Legis, Salamanca, 2004 ). En fin, como señala M. Villoria Mendieta, existe ya una base de reflexión suficiente sobre la materia (pág. 12).

3 "Prefacio", en A. J. HEIDENDEIMER \& M JOHNSTON (editores), Political Corruption. Concepts \& Contexts, $3^{\mathrm{a}}$ ed. Londres, 2002 Precisamente dos autores que no pueden ser considerados unos "recién llegados" a la cuestión dada la trayectoria y enorme aportación en especial de los trabajos del primero (tanto monográficos como de coordinación y selección de los textos "canónicos" en la materia) desde los años 70. (no en vano el trabajo recién citado aparece como $3^{a}$ edición aunque realmente más que de ediciones debería hablarse — como hacen los autores- de dos volúmenes precedentes, de 1970 y 1989).

4 A. SAJÓ, "Introduction: Clientelism and Extortion: Corruption in Transition" en A. Sajó y S. Kotkin, Political Corruption in Transition, . A Skeptics Handbook, CEU press, 2002, pág. 2.

5 J.B. JACOBS, "Dilemmas of Corruption Control" en A. SAJÓ - S. KOTKIN, Political Corruption in Transition, . A Skeptics Handbook, citado en la nota anterior, pág. 81.

6 Ibidem, respectivamente pág. 2 y pág. 82.

7 J. B. JACOBS, ibidem. 
otra, incidirían a menudo en la vida personal de éstos y, por último, pondrían de manifiesto la fractura cada vez más acusada entre el comportamiento esperado y el comportamiento real de los gobernantes de modo que al final e "irónicamente somos víctimas de nuestra propia cruzada moral ${ }^{8}$. La ética, en concreto la ética pública o la ética política (no la ética personal del gobernante) tiene, como veremos, algún tipo de papel que cumplir en el concepto de corrupción política. Pero, sostiene Uhr' ${ }^{9}$, no puede sobredimensionarse tal papel; debe mantenerse en su sitio que, por otra parte, es razonablemente modesto desde la perspectiva del análisis jurídico del concepto. En este sentido debe tenerse muy en cuenta que la ética exigible a los gobernantes está "atrapada en el contexto cultural y en las creencias de su tiempo y lugar" sin que quepa establecer unas exigencias de comportamiento tan estrictas que acaben interfiriendo de manera permanente en el proceso político pues, no conviene olvidarlo, el juez último del comportamiento del gobernante democrático no es otro que el pueblo constituido en cuerpo electoral ${ }^{10}$.

Por otra parte, como se ha señalado unánimemente, debe destacarse que poder y corrupción son términos inseparables. Toda forma de poder ha tenido corrupción y probablemente nos encontremos en el momento histórico donde ésta existe en menor medida si lo comparamos con la larga historia de la humanidad ${ }^{11}$. Es probablemente ahora, en un sistema plenamente de-

8 Así un planteamiento razonable de las cuestiones relacionadas con la corrupción política puede requerir la propuesta de medidas absolutamente impopulares plenamente alejadas del buenismo. En tal sentido no se puede sino destacar la afirmación de Lord Nolan cuando sugiere que no puede exigirse tanto a los políticos cuando se da muy poco a cambio por lo que propone un fuerte aumento de sus sueldos ("money is not everything, but is much easier to be moral if you can afford it. A democracy undervalues its politicians at its peril", en "Motivating Ministers to morality" en J. FLEMING \& I. HOLLAND, Motivating Ministers to Morality, Aldershot, 2001, pág. 20). Algo parecido deberíamos sostener respecto a la financiación ilegal de los partidos políticos vista por la inmensa mayoría de los autores como la fuente de gran parte de las corrupciones. No se puede si no estar de acuerdo con Sajó (citado, pág. 16) cuando sostiene que si la financiación de los partidos y las elecciones están cada vez más sujetas a normas restrictivas y la demanda para gastos electorales es cada vez mayor, entonces resulta claro que el camino a la ilegalidad es casi inevitable. Por tanto, debemos sostener nosotros, probablemente sea más eficaz aumentar su financiación que las penas por hacerlo ilegalmente. Aunque sea impopular o moralmente cuestionable.

9 Véase, J. UHR, "Motivating Ministerial Ethics: Putting Political Ethics in its Place", en J. FLEMING \& I. HOLLAND, Motivating Ministers to Morality, Aldershot, 2001, págs. 187 y ss. Por estos motivos sostiene Nieto que es necesario teorizar la corrupción sin referencia a la ética sino a las reglas del juego político o de la convivencia democrática, véase, Corrupción en la España democrática, citado, especialmente, págs. 78 y ss.

$10 \mathrm{El}$ argumento y la cita proceden de R.J. JACKSON, "Honesty and corruption in the Canadian Federal Government", incluido en la obra recién citada de J. FLEMING \& I. HOLLAND, pág. 108.

11 Resulta verdaderamente ilustrativa (aún diría que hasta "educativa") la lectura del "almanaque de la corrupción" desde 1776 en Estados Unidos de K. LONG (The Almanac of Political Corruption, Sscandals and Dirty Politics, Delta Books, Nueva York, 2008), pese a que probablemente destruya parte del respeto sentido hacia grandes mitos de la historia constitucional norteamericana. 
mocrático ${ }^{12}$, cuando mayor preocupación exista por el fenómeno, mayores medidas y financiación para erradicarla y, en fin, mayores éxitos en la lucha contra ella. No conviene caer pues en un exceso de alarmismo, ni convertir a los estudiosos de la cuestión en moralistas demasiado identificados con su objeto de estudio.

Lo que en estas páginas se pretende es, aparentemente, cumplir con un objetivo muy modesto. Proponer un concepto útil de corrupción política para el jurista de modo que desde el derecho constitucional se puedan abordar otros tres objetivos ${ }^{13}$ : explicar la importancia del fenómeno para la vigencia de la Constitución, analizar los problemas constitucionales planteados y proponer, en su caso, líneas de actuación que probablemente deberían ser tanto educativas como institucionales ${ }^{14}$. Estos tres últimos objetivos deberán dejarse para más adelante puesto que, sólo con el primero de índole conceptual ya tenemos suficientes dificultades y problemas que afrontar. No se trata de formular un concepto jurídico de corrupción política. Se busca, y las palabras no son casuales, un concepto útil para el jurista.

Así planteado, el camino a seguir requiere los siguientes pasos: desbrozar las distintas perspectivas de análisis; adoptar un concepto útil o, como veremos, más bien un modelo jurídicamente operativo de análisis; extraer las consecuencias jurídico-constitucionales oportunas del anterior concepto a partir de la Teoría Constitucional para establecer las fuentes de las normas de referencia aplicables a la corrupción política; adaptar esas fuentes a la Realidad Constitucional actual y destacar las principales dificultades encontradas en su definición para lo que utilizaremos la experiencia constitucional británica y abogar por una posible solución a algunos de los problemas de indeterminación normativa presentes en España con la adopción de códigos de conducta

12 No debe olvidarse nunca que un sistema democrático asentado en el Estado de Derecho es sin lugar a dudas el mejor preparado para enfrentarse a la corrupción. Véase, desde dos perspectivas diferentes pero ambas muy contundentes, F.J. LAPORTA y S. ALVAREZ, "Presentación" en La corrupción política, citado, págs. 28 y ss y el ya clásico e influyente trabajo de S. ROSE y ACKERMAN, Corruption and Government, Cambridge University Press, 1999, especialmente, págs. 127 y ss. Aunque también debe resaltarse que también en el sistema democrático es probablemente donde más devastadores sean los efectos de la corrupción en cuanto suponen una alteración de los principios básicos de regulación de la toma de decisiones sobre la base del respeto a los deseos de los gobernados, véanse por todos las aportaciones de F.J. MALEM SEÑA ("El fenómeno de la corrupción", en el ya citado trabajo editado por F.J. LAPORTA y S. ALVAREZ, La corrupción política, pág. 87 y en La corrupción. Aspectos éticos, económicos y jurídicos, citado págs. 121-127) y A. NIETO (Corrupción en la España democrática, citado, págs. 266 a 269).

13 A algunas de estas cuestiones (en lo atinente al control parlamentario) nos hemos referido en "Corrupción de los gobernantes, responsabilidad política y control parlamentario", en esta misma revista, págs. 135 y ss.

14 Sobre la posibilidad de encuadrar las medidas contra la corrupción en estos dos grandes tipos de objetivos véase el excelente trabajo de H. PATAPAN, "Educating Devils: Theoretical Reflections on Ethics and Governance", en J. FLEMING \& I. HOLLAND, Motivating Ministers to Morality, citado, págs. 21 y ss. En particular sobre las llamadas medidas educativas y sus problemas también resultan de pleno interés las reflexiones de F.J. MALEM SEÑA, "Corrupción, racionalidad y educación moral", citado. 
que habrán de reunir una serie de características para poder cumplir adecuadamente la misión encomendada.

\section{DIFICULTADES EN EL ESTUDIO JURÍDICO-CONSTITUCIONAL DE LA CORRUPCIÓN POLÍTICA COMO CONSECUENCIA DE LA CONCURRENCIA DE PUNTOS DE VISTA HETEROGÉNOS}

El estudio de la corrupción política presenta como dificultad esencial la proliferación de trabajos que abordan la cuestión desde perspectivas diferentes y desde ramas del conocimiento metodológicamente muy dispares. Es obvio que la interdisciplinariedad es una característica positiva en la medida en que permite el análisis de una misma cuestión desde punto de vista diferentes lo que añade riqueza y seguridad al detectar los elementos esenciales y todos los matices del fenómeno objeto de estudio. Sin embargo, este tipo de análisis verdaderamente complementarios ${ }^{15}$ son extraordinariamente escasos y, a menudo, insatisfactorios. El problema respecto a la corrupción política es, a mi juicio, que la perspectiva de análisis condiciona de tal manera el concepto utilizado que hace imposible reconocer un idéntico objeto de estudio. Por ello, si deseamos encontrar un concepto de corrupción política útil para el jurista debemos primero apuntar cuáles son las aproximaciones habituales para su definición y cuáles los puntos débiles que las mismas presentan desde la óptica del análisis jurídico-constitucional, sin olvidar que pese a esas debilidades, las diferentes formas de aproximación son, a la postre y en diferente medida, complementarias entre sí por lo que confieren ideas o reflexiones de plena utilidad para el citado análisis jurídico constitucional.

Sin embargo para realizar tal análisis debemos adoptar un primer concepto de corrupción política que nos sirva de partida para establecer las diferentes formas de aproximación. En tal sentido desde la filosofía del derecho en nuestra propia doctrina, Malem ${ }^{16}$ nos suministra un concepto plenamente útil desde el que plantear las diferentes perspectivas, incluida la adoptada en este texto. Así, entiende corrupción como "violación de un deber posicional realizado por quien ostente un cargo o cumple alguna función determinada

$15 \mathrm{Al}$ respecto véase, M. PHILIP, "Political corruption, democratization and reform", en A. SAJÓ y S. KOTKIN, Political Corruption in Transition,. A Skeptics Handbook, citado, pág. 57 o, en nuestro idioma la queja de F. GIL VILLA, La cultura de la Corrupción, Maia editores, Madrid, 2008, pág. 9.

16 Tomamos la primera referencia temporal en F.J. MALEM SEÑA, "El fenómeno de la corrupción", en el ya citado trabajo editado por F.J. LAPORTA y S. ALVAREZ, La corrupción política, pág. 80. El profesor Malem mantendrá en muy parecidos términos la definición reproducida en sus trabajos de 2000, 2002 y 2007 (ya citados). Parecidas definiciones proveen Laporta o E. Garzón Valdés, "Acerca del concepto de corrupción" en el libro editado por el primero, que, además, define claramente los conceptos de sistema normativo relevante, los deberes posicionales, ganancias extraposicionales y va ofreciendo sucesivas y más perfeccionadas definiciones de corrupción a lo largo del texto. 
por cierto sistema de reglas efectuado con motivo del ejercicio de un cargo o del cumplimiento de la función y realizada en un marco de discreción, con el objeto de lograr algún beneficio extraposicional». En definitiva debe aparecer en la definición la violación de un deber conforme a un "sistema normativo de referencia", realizado con discreción y para obtener un beneficio diferente de los propios del cargo ocupado.

Tomando como referencia tal concepto podemos ya establecer dos tipos diferentes de aproximación a la corrupción política. Uno condicionado por su estudio desde una aproximación que podríamos llamar corrupción política agregada o sistémica (si se quiere macrocorrupción) y otra condicionada porque el objeto principal de preocupación en el análisis sea la conducta corrupta individual (si se quiere de la microcorrupción).

\subsection{LA CORRUPCIÓN COMO CONCEPTO RETÓRICO, GENERAL O AGREGADO. \\ LA CORRUPCIÓN EN SENTIDO “MACRO» FRENTE A LA CORRUPCIÓN EN SENTIDO «MICRO»}

Corrupción es un significante que "huele mal", es "vil y repugnante para los sentidos físicos " ${ }^{17}$. Apesta. Efectivamente, y así se ha destacado desde la totalidad de los estudiosos, ya el propio término denota una valoración negativa; un proceso físico de degeneración ${ }^{18}$, sin posibilidad de retorno, pues el órgano corrupto no volverá a ser sano. Una contaminación irreversible del cuerpo particularmente desagradable y, a menudo, inevitable. Hasta los antónimos denotan esa valoración. Lo contrario a corrupto es sano. Lo "incorrupto" es algo más. Algo sagrado o bendecido, probablemente contrario a la lógica racional de la vida humana.

Al conceptualizar la corrupción política esta perspectiva es a menudo la adoptada cuando usamos el término, señala Garzón Valdés ${ }^{19}$, desde una dimensión retórica y no desde una dimensión concreta. En tal dimensión, la corrupción política es la degeneración de un cuerpo político, de una comunidad. Así lo plantea ya claramente Friedrich ${ }^{20}$, recordando a Lord Acton, cuando entiende la corrupción como un proceso de depravación moral visible en toda forma de gobierno, esto es, como una forma de patología política general. En tales estudios constituyen referencias inevitables la definición aris-

17 R.C. BROOKS, "The Nature of Political Corruption", en A.J. HEIDENDEIMER (ed), Political Corruption. Readings in comparative analysis, Nueva Jersey, 1970, pág. 57

18 De "decadencia, desintegración, degeneración o envilecimiento" habla J.F. MALEM SEÑA en "El fenómeno de la corrupción", citado, pág. 73 en parecidos términos puede leerse la opinión de A. NIETO en Corrupción en la España democrática, citado, pág. 75.

19 E. GARZÓN VALDÉS, "Acerca del concepto de corrupción", citado, págs. 50-51.

20 C.J. FRIEDRICH, "Corruption Concepts in Historical perspective", en A.J. HEIDENDEIMER \& M. JOHNSTON, Political Corruption. Concepts and Contexts, citado, págs. 15 y ss (aunque se trata de un fragmento extraído de C.J. FRIEDRICH, The Patology of Politics: Violence, Betrayal, Corruption, Secrecy and Propaganda, Nueva York, 1972). 
totélica de las formas de gobierno (donde las formas puras e impuras se establecen a partir de su corrupción o no), su carácter cíclico en Polibio (siendo la corrupción la fuerza impulsora de la interminable dinámica de cambio de una a otra) o, en fin, su inevitabilidad como consecuencia de los evidentes e inevitables fallos de la agustiniana Ciudad de los Hombres frente a la perfección de la Ciudad de Dios ${ }^{21}$.

En estas aproximaciones ${ }^{22}$ resulta lógico identificar en la perdida de las virtudes ciudadanas la causa general de este proceso de corrupción de la forma de gobierno. Sea la virtù cívica en los términos añorados por Maquiave$\mathrm{lo}^{23}$, sea la virtud republicana señalada por Montesquieu como una de las causas del ascenso y caída de la república romana ${ }^{24}$, sea la virtud deseada por los representantes del nuevo republicanismo, sea la virtud perdida del buen salvaje rousseaniano pervertido por las ansías de poder del resto de individuos $^{25}$. Es pues en las causas de la pérdida de la virtud ciudadana o en los medios para evitar que ésta desaparezca donde estos estudios centran sus análisis.

Esta no es la perspectiva adoptada en este trabajo. Nuestro objetivo es mucho más modesto y sólo pretende la definición individualizada de la corrupción política o, lo que es lo mismo, la definición de cuándo un determinado comportamiento puede calificarse de políticamente corrupto. Ahora bien, la aproximación recién apuntada nos ofrece importantes percepciones sobre las que habremos de volver. Por una parte, la gravedad de una generalización de la corrupción por su efecto destructor de la democracia (en nuestro caso) en cuanto forma de gobierno ${ }^{26}$. Por otra, la idea de virtud cívica como elemento relevante a la hora de definir corrupción política.

En definitiva, las aportaciones de la percepción macro de la corrupción política no deben ser olvidadas, sin más, a la hora de tratar su definición des-

21 Así FRIEDRICH destaca esta conexión en la tradición cristiana dada la intrínseca maldad del poder terrenal, ibidem, pág. 16.

22 Véase el claro repaso a estos planteamientos en H. PATAPAN, «Educating Devils: Theoretical Reflections on Ethics and Governance", citado, págs. 21 y ss.

23 Véase el interesante trabajo (usado por cortesía del autor) en este mismo número de E. GARCÍA LÓPEZ, "Istorie Fiorentini de Maquiavelo: una primera definición moderna de corrupción", o las constantes referencias a la virtù tal y como la entiende Maquiavelo en los trabajos citados de Fiedrich

24 C.J. FRIEDRICH, ibidem, págs. 18 y 19 refiriéndose fundamentalmente a Considérations sur les causes de la Grandeur des Romains et de leur Décadence (primera edición de 1734).

25 C.J. FRIEDRICH, ibidem, pág. 19.

26 No es sólo un problema cuantitativo, es también un problema cualitativo en dos sentidos Por una parte, la corrupción genera una "espiral creciente", aunque el nivel de corrupción política en un Estado y momento histórico concretos sea reducida no debe perderse de vista que su mera existencia pone en marcha procesos de crecimiento de la misma que pueden acabar provocando su generalización. Sobre el tema véase L. NEWELL \& M.J. BULL, "Conclusion" en el libro por ellos editado Corruption in Contemporary Politics, Palgrave, Londres, 2003, pág. 240. Por la otra, como se verá en el texto, la corrupción política genera un inevitable efecto de desafección ciudadana hacia la forma de gobierno democrática en particular. 
de una perspectiva micro como la adoptada en este trabajo ${ }^{27}$. Pero tampoco debemos olvidar el efecto de la corrupción individualizada sobre la comprensión retórica de la corrupción porque un concreto acto de corrupción tiene, a juicio de Girling ${ }^{28}$ un fuerte componente simbólico al menos en cuatro sentidos: rompe la confianza en el sistema; populariza la idea de corrupción generalizada aunque no sea cierta; presupone la existencia de otros casos desconocidos y produce un efecto general de desánimo. De este modo esta corrupción simbolizaría la "podredumbre de la política, o del Estado o incluso de la propia sociedad".

\subsection{OBJETOS DE ANÁliSIS HETEROGÉNEOS EN LA COMPRENSIÓN DE LA CORRUPCIÓN POLÍTICA}

En el caso del estudio de la corrupción desde una dimensión concreta o desde un análisis micro nos encontramos la dificultad de que las distintas aproximaciones se centran en aspectos diferentes lo que hace incompatibles o intrasladables sus principales conclusiones. En este sentido podemos clasificar estas aproximaciones según cuál sea el centro de gravedad del estudio realizado en los siguientes grupos ${ }^{29}$ :

A) Aproximaciones centradas en el interés público. En este tipo de estudios se define la corrupción como ejercicio de una competencia pública con la finalidad de obtener un beneficio personal dañando el interés de los ciudadanos. La presencia de este daño el interés público es uno de los elementos esenciales (si no el único) del propio concepto de corrupción política frente a otros comportamientos en los que no existe tal daño o simplemente no hay interés público lesionado. Los problemas evidentes de esta aproximación radican en, por una parte, la dificultad en definir en concreto la idea de interés público y, por la otra, en la discutible afirmación de que donde no haya lesión a aquél no hay corrupción.

27 El uso de los terminos "macro" o "micro" para la corrupción procede de M. VILLORIA MENDIETA. La corrupción política, citado, pág. 21.

28 J. GIRLING, Corruption, Capitalism and Democracy, Routledge, Londres-Nueva York, 1997, pág. 26 y 151 respectivamente.

29 Seguimos aquí de cerca las clasificaciones y las valoraciones realizadas a los distintos tipos de definición por A.J. HEIDENHEIMER en su introducción a la primera parte de, Political Corruption. Concepts \& Contexts, citado, págs. 5 a 10, en la misma obra la aportación de M. PHILP, "Conceptualizing Political corruption" págs. 41 y ss; el pormenorizado estudio de las distintas perspectivas realizado por M. VILLORIA MENDIETA, La corrupción política, citado, págs. 25 a 72; las distintas reflexiones de L. NEWELL \& M.J. BULL, "Introduction" en el libro por ellos editado Corruption in Contemporary Politics, Palgrave, citado, págs. 1 y ss; J. GARDINER, "Defining corruption", en el libro ya citado editado por HEIDENHEIMER \& JOHNSTON, Political Corruption. Concepts \& Contexts, págs. 29 a 36 y R. HARRIS, Political Corruption, In and Beyond the State, Routledge, Londres-nueva York, 2003, pp 1-10; 
B) Aproximaciones centradas en el cargo público ejercido. En estos planteamientos la corrupción aparece definida como el incumplimiento de los deberes derivados del ejercicio de un cargo público con la finalidad de obtener beneficios privados. El problema en este tipo de supuestos es determinar con exactitud cuáles son los deberes inherentes al cargo público afectado. Si se hace con referencia a las normas jurídicas reguladoras del mismo nos encontraremos con situaciones no previstas (ver infra D) y si no se hace con referencia a normas jurídicas caeremos de nuevo en situaciones de indeterminación de la conducta exigida.

C) Aproximaciones centradas en el intercambio económico realizado. Una importante corriente de pensamiento procedente de la economía o del análisis económico del derecho estudia el fenómeno a partir de sus efectos económicos más característicos bien como mecanismo sustitutivo del mercado, bien desde la óptica de la maximización de los beneficios económicos derivados del ejercicio del cargo, bien de su efecto beneficioso o no sobre el desarrollo y estabilidad económica o incluso de su relación con los intercambios económicos entre Estados o como elemento caracterizador de las economías subdesarrolladas. Si bien este tipo de aproximaciones pueden ofrecer importantes datos respecto al funcionamiento de las diferentes formas de corrupción (y por tanto respecto a las fórmulas jurídicas para luchar contra ella desincentivando los comportamientos corruptos) resultan, en general, poco útiles desde la aproximación pretendida en estas páginas que en definitiva requiere un concepto no sólo empírico sino también normativo.

D) Aproximaciones centradas en la infracción de normas jurídicas. En este caso se entiende por corrupción, y en concreto corrupción política, el conjunto de comportamientos definidos como tales en las normas jurídicas. Esta perspectiva sin embargo parece insuficiente en la medida en que muchos comportamientos que podríamos definir como corruptos no aparecen expresamente prohibidos por el ordenamiento jurídico, incapaz de prever todas las variedades, o simplemente no están verdaderamente vigentes porque no es posible su aplicación en la práctica o su demostración en un juicio penal ${ }^{30}$. Por otra parte, podríamos encontrarnos situaciones en las que determinados actos sean jurídicamente corruptos (en cuanto prohibidos por el ordenamiento), pero nadie los calificaría como corruptos por estar ética o políticamente justificados . En fin, como trataremos de demostrar más adelante, también es posible que en el caso de la corrupción de los políticos no sea razonable aplicar los mismos parámetros de juicio (las normas jurídicas) que a los ciudadanos que no han sido democráticamente elegidos. Así, coincidimos con Villoria Mendieta ${ }^{31}$ en que las definiciones jurídicas son «demasiado es-

30 Por ejemplo el llamado (y últimamente muy conocido) delito de cohecho impropio impide la aceptación de regalos a cargos públicos y funcionarios, más allá de otros problemas que se examinarán más adelante, pero nada dice respecto a la posibilidad de que se hagan regalos a personas allegadas al funcionario o cargo afectado (llámese pareja, hijos u otro tipo de familiares).

31 M. VILLORIA MENDIETA, La corrupción política, citado, págs. 33-34. 
trechas" dejando fuera comportamientos que son reprobables (aunque no constitutivos de infracción legal demostrada) y que pueden acabar, eventualmente, poniendo en peligro por su generalización el propio sistema democrático, pues, señala Brooks ${ }^{32}$, "las sanciones de la ley positiva se aplican sólo a los prácticas más flagrantes en los que la experiencia demuestra que son tan perniciosos que tal sentimiento ha cristalizado en prohibiciones legales y en decisiones judiciales condenatorias"

E) Aproximaciones centradas en la infracción de otros tipos de normas (éticas, deberes politicos). Esta visión de la corrupción juzga como tal aquellas conductas que cumpliendo los objetivos y presupuestos ya examinados (ejercicio de un cargo público, existencia de un beneficio privado) supone la infracción de normas éticas o de deberes políticos. En este supuesto resolvemos el problema de estrechez de las normas jurídicas, pero caemos de nuevo en la indeterminación. No es posible determinar con la mínima certeza exigida por los análisis jurídicos cuáles son las normas éticas o los deberes políticos exigibles a un representante político. Se tratará de normas cambiantes según la personal ética de cada uno, la propia visión del deber político. No será posible encontrar, en las sociedades actuales, una ética común a todas las perspectivas ideológicas. Por otra parte serán normas cambiantes según tiempos y lugares de modo que comportamientos éticamente irreprochables en determinados momentos históricos de un determinado Estado pueden devenir corruptos en otras situaciones o contextos. Igualmente lo considerado éticamente corrupto en, pongamos por caso, determinadas culturas, países o, incluso, en zonas de un mismo país puede ser muy diferente.

F) Aproximaciones centradas en la definición social de corrupción. En este tipo de estudio de la corrupción se trata de determinar qué comportamientos son considerados corruptos a partir de la propia idea social predominante. Aquí encontraríamos solución al problema de indeterminación característico de la aproximación anterior y a la estrechez de los conceptos jurídicos. Sin embargo, encontramos problemas nuevos a partir de la metodología utilizada para concretar el concepto. Por una parte se puede utilizar técnicas de investigación sociológica, sin embargo dada la naturaleza opaca de toda corrupción (y en particular de la corrupción política) probablemente midamos más la percepción social de la corrupción (como se hace en la mayoría de los estudios modernos sobre el tema) que la comprensión social de lo que se considera corrupto o no. Además este tipo de investigaciones vendrá condicionado de manera determinante por el tratamiento informativo que desde los medios de comunicación se esté dando a los escándalos políticos del momento (y escándalo no es lo mismo que corrupción). Otras aproximaciones propuestas parecen insuficientemente fiables desde las exigencias de certeza que atenazan al jurista: la communis opinio de la élite intelectual o los criterios de valoración de los grandes medios de comunicación no aparecen como parámetros suficientemente fiables para evaluar desde el derecho el fenómeno

32 R.C. BROOKS, "The Nature of Political Corruption", citado, pág. 56. 
de la corrupción. Desde otra perspectiva nos encontraremos con situaciones que Heidenheimer ha clasificado, con notorio éxito en la doctrina, como corrupción política blanca, gris o negra, siendo la primera un caso evidente de percepción social de la corrupción como existente pero tolerada que puede llegar a situaciones de auténtica cultura social de la corrupción. En fin, definiciones como estas hacen inviable un análisis jurídico constitucional fiable.

G) Aproximaciones centradas en el efecto de la corrupción sobre la Política. Esta forma de estudiar la corrupción se focaliza en los sistemas democráticos con valores compartidos comunes en torno a la vigencia de los derechos fundamentales y se centra en estudiar el efecto demoledor de la corrupción sobre la política democrática. En las palabras finales de uno de sus más brillantes defensores ${ }^{33}$, no se trata tanto de estudiar la corrupción política o de los políticos, cuanto de la corrupción de la política y, en concreto, de la política democrática. En este caso nos encontramos más ante una aproximación desde una dimensión retórica (en el sentido antedicho como macrocorrupción), por otra parte, de enorme utilidad (pues al centrarse no en cualquier forma de gobierno sino solo en la democrática y en sus efectos sobre esta nos va a dar indudables ideas plenamente utilizables en el análisis jurídico), pero que a la hora de concretar los parámetros de conducta para juzgar la corrupción de los gobernantes democráticos nos acaba llevando o bien a ideas demasiados abstractas (el interés general o de los ciudadanos) o a normas no suficientemente concretas.

En esta panorámica general se ha tratado de apuntar los principales tipos de análisis utilizados para estudiar la corrupción política. Ninguno nos resulta plenamente satisfactorio para nuestro objetivo (un concepto útil para el análisis de la corrupción política desde el derecho constitucional), pero, desde luego, en todos ellos (obviamente en unos más que en otros) encontramos ideas importantes para desarrollar la materia objeto de nuestra actual preocupación. En particular, las dificultades en la determinación de las normas infringidas en un acto corrupto será uno de los principales problemas porque, al fin y al cabo, la fijación con certeza del marco normativo de referencia en la definición general de Malem apuntada al principio de este apartado es una de las tareas esenciales e irrenunciables del jurista.

\section{UN CONCEPTO ÚTIL PARA EL ANÁLISIS JURÍDICO: EL MODELO PRINCIPAL-AGENTE}

\section{III.1. UN MAPA ANALÍTICO DE LA CORRUPCIÓN: EL MODELO PRINCIPAL-AGENTE}

Una forma de aproximación, a nuestro entender, útil para el análisis jurídico de la corrupción política procede de la Economía y de la Sociología fun- 
damentalmente y consiste en la aplicación de modelos de análisis sustentados en la relación principal-agente ${ }^{34}$. Puede que sea cierta la crítica de quienes consideran que este tipo de análisis no lleva tanto a un concepto como a una pura descripción, pero aún así constituye una descripción plenamente útil para lo que estamos buscando que no es otra cosa que permitir una determinación de todos los elementos del concepto capaz de ser objeto de análisis jurídico constitucional.

En la descripción del modelo nos parece que la aportación de Gambetta ${ }^{35}$ resulta particularmente esclarecedora en cuanto pretende establecer una suerte de mapa analitico de la corrupción. Esto es, un conjunto de rasgos específicos y comunes a todo tiempo y lugar cuyo contenido concreto puede ser cambiante, pero que han de estar presentes para que podamos hablar de corrupción en general. Para ello trata de alejarse intencionadamente de consideraciones jurídicas, éticas y económicas.

El caso "tipo" descrito por Gambetta ${ }^{36}$ requiere la presencia de tres actores en todo fenómeno de corrupción. El sujeto que confiere la confianza (trust) a un tercero para gestionar determinados recursos ( $\mathrm{T}$, en cuanto truster $)^{37}$ que actúa como principal; el agente que la recibe (F, en cuanto Fiduciario) y el corruptor (C). T podrá ser un sujeto individual o colectivo. $\mathrm{F}$ es alguien que actúa en nombre de T. Y C es alguien cuyos intereses se ven afectados por las acciones de $\mathrm{F}$.

El esquema básico de funcionamiento, siempre siguiendo a Gambetta, de la corrupción sería: $\mathrm{C}$ quiere recursos que se supone que $\mathrm{F}$ no puede darle dadas las condiciones de su relación con T. Por ello de alguna manera C compra a $\mathrm{F}$ para que a pesar de la citada relación con T le confiera los recursos deseados. Este esquema presupone la existencia de una relación anterior al comportamiento corrupto entre el principal $\mathrm{T}$ y el agente $\mathrm{F}$. Una relación que se explica a partir de un "juego de confianza básica", en el que T acepta encomendar determinados recursos a $\mathrm{F}$ en cuanto espera que servirá sus intereses y no su propio interés personal. Para ello $\mathrm{T}$ y $\mathrm{F}$ acuerdan una serie de reglas vinculantes de las acciones correctas que $\mathrm{F}$ ha de llevar a cabo $\left(\mathrm{a}_{\mathrm{r}}\right.$, right actions) y de las acciones que se consideran erróneas $\left(\mathrm{a}_{\mathrm{w}}\right.$, wrong actions). Para el principal $\mathrm{T}$, el conjunto de acciones $\mathrm{a}_{\mathrm{r}}$ siempre será preferido al conjunto $\mathrm{a}_{\mathrm{w}}$ de modo que si piensa que el agente $\mathrm{F}$ va actuar infringiendo las reglas preestablecidas estará mejor no confiriéndole la gestión de recursos

34 Tomamos ya este modelo como referencia en nuestro trabajo ya citado "Corrupción de los gobernantes, responsabilidad política y control parlamentario", en este misma revista, págs. 138139. Modelos principal-agente son, con matices, utilizados por S. ROSE-ACKERMAN o NEWELL y BULL (incluyendo el buen trabajo de Holmes incluido en el trabajo editados por éstos) en sus respectivos trabajos ya citados.

35 D. GAMBETTA, "Corruption: An analytical Map" en S. KOTKIN \& A. SAJÓ (eds), Political Corruption in Transition. A Skeptics Handbook, citado, págs. 33 y ss.

36 Ibidem, págs. 35 a 39.

37 Mantenemos los términos en inglés no sólo para respetar la autoría del modelo sino porque ello, como se apuntará, tiene importancia en el hilo argumentativo del texto. 
transmitida $^{38}$. Para evitar rupturas involuntarias de las reglas o la comisión de errores, $\mathrm{F}$ debe conocer perfectamente las preferencias de $\mathrm{T}$ ordenando con claridad $\mathrm{a}_{\mathrm{r}} \mathrm{y} \mathrm{a}_{\mathrm{w}}$. La corrupción es, por tanto, una ruptura por parte de $\mathrm{F}$ de la relación de confianza (trust) al hacer $\mathrm{a}_{\mathrm{w}} \mathrm{O}$ al dejar de hacer $\mathrm{a}_{\mathrm{r}}$ como consecuencia del beneficio obtenido procedente de C. Nótese, no es ocioso insistir, que para que el intercambio corrupto se produzca, T debe previamente haber reclutado a $\mathrm{F}$ puesto que si no tiene capacidad de decisión no tiene capacidad real para romper la relación con de confianza. Por ello, F tiene que ser, necesariamente, un agente digno de la confianza de $\mathrm{T}$.

En este modelo suele darse un "juego de apariencias" puesto que si $\mathrm{F}$ quiere continuar obteniendo los beneficios suministrados por C, deberá seguir aparentado que es digno de la confianza depositada en cuanto esta podría serle retirada (y con ello la capacidad de decisión involucrada) inmediatamente, produciéndose lo que Garzón Valdés, denomina una suerte de "adhesión retórica al sistema normativo de referencia ${ }^{39}$. Por ello, será habitual que estos comportamientos se mueven en el terreno de lo secreto que, sin embargo, no será necesario cuando la corrupción sea generalizada pues bastará la mera hipocresía de todos los agentes implicados.

Los concretos motivos de la desviación de $\mathrm{F}$ respecto a las reglas establecidas por el principal $\mathrm{T}\left(\mathrm{a}_{\mathrm{r}} \mathrm{y} \mathrm{a}_{\mathrm{w}}\right)$ son, para Gambetta, irrelevantes, pero deben ser consecuencia del intercambio con $\mathrm{C}$. Esto es, $\mathrm{C}$ ha de ofrecer algo $\left(\mathrm{M}^{*}\right)$ a $\mathrm{F}$ para que este ignore las reglas de modo que $\mathrm{a}_{\mathrm{w}}+\mathrm{M}^{*}$ sea, para el agente $\mathrm{F}$, preferido $\mathrm{a} \mathrm{a}_{\mathrm{r}}$.

Este esquema básico presenta tres variantes interesantes: aquellas en las que F y C coinciden (corrupción de tipo nepotística en la definición del autor citado, aunque puede abarcar supuestos diferentes de lo habitualmente considerado como nepotismo); aquellos en los que la presión no es de $\mathrm{C}$ a $\mathrm{F}$, sino al revés (corrupción extorsionadora) y aquellos en los que no $\mathrm{C}$ pide tanto una actuación en contra de las reglas establecidas sino "fuera de ellas" buscando una especie de "mejor servicio".

Este es el esquema básico para el análisis de la corrupción utilizado por Gambetta. Conviene ahora que lo adaptemos a la corrupción política.

III.2.- La corrupción politica como forma especial de corrupción según el modelo agente-principal.

El modelo principal-agente descrito es muy útil para el análisis de la corupción política en un sistema democrático asentado en la idea de representación que tan adecuadamente se ve reflejado en este modelo.

Efectivamente, T en el caso de la corrupción política es el sujeto principal que transfiere la confianza política (trust). En ocasiones es un sujeto colectivo (el pueblo en elecciones o los miembros de una cámara parlamentaria o un ente representativo o deliberativo) y en otras ocasiones es un sujeto individual

38 Si bien, señala Gambetta puede ocurrir que $\mathrm{T}$ acepte $\mathrm{a}_{\mathrm{w}}$ de F como "segunda mejor opción" en cuanto que no encuentre a ningún $\mathrm{F}$ que lo haga mejor.

39 E. GARZÓN VALDÉS, "Acerca del concepto de corrupción", pág. 49. 
que designa a alguien para colaborar en la gestión de intereses colectivos, pero que en alguna medida está a su vez sujeto a una relación de confianza con terceros (por ejemplo, un Ministro está sujeto a la relación de confianza establecida con $\mathrm{T}_{3}$ - el presidente del gobierno- que a su vez está sujeto a una relación de confianza con $\mathrm{T}_{2}$ —el Congreso de los Diputados- cuyos miembros están sujetos a otra relación de confianza con $\mathrm{T}_{1}$ —el cuerpo electoral-). De esta forma en todo sistema democrático encontraremos como sujeto último que confiere la confianza (trust) al pueblo $\left(\mathrm{T}_{1}\right)$ si bien esta se extiende a través de una cadena de confianzas más o menos larga ${ }^{40}$ a todos los sujetos que ejercen cargos públicos y que se convierten, de este modo, en fiduciarios directos $\left(\mathrm{F}_{1}\right)$ o indirectos $\left(\mathrm{F}_{2-\mathrm{n}}\right)$ del pueblo.

Dado que la participación democrática se articula a través de los partidos políticos el esquema ha de poder aplicarse sin grandes dificultades también a los partidos políticos en cuanto respeten un funcionamiento democrático interno. Así, los militantes - $\mathrm{T}_{1}$ - confieren una relación de confianza (trust) a sus representantes y compromisarios ante la asamblea general del partido $-\mathrm{F}_{1}$ - que a su vez $-\mathrm{T}_{2}$ - se la transmiten a los componentes de los órganos directivos $-\mathrm{F}_{2}-$ del partido que, en ocasiones, $-\mathrm{T}_{3}$ - podrán nombrar a terceros para colaborar en la gestión del partido $-\mathrm{F}_{3}-$, por ejemplo asesores de la dirección del partido.

En virtud de cada relación de confianza política $\mathrm{T}$ impone una serie de normas acerca de lo considerado correcto e incorrecto en la gestión de los intereses comunes que ha sido transmitida (las ya conocidas $\mathrm{a}_{\mathrm{r}} \mathrm{y} \mathrm{a}_{\mathrm{w}}$ ). Si bien ha de tenerse en cuenta que dado el esquema de cadena de confianzas, tanto los sujetos que las otorgan como la finalidad de la confianza son diferentes por lo que muy probablemente las reglas deban ser también distintas (así hablaremos de $a_{r 1-n} y$ de $a_{w 1-n}$ ) lo que, por otra parte, parece intuitivamente muy razonable $^{41}$. No es lo mismo la relación de confianza entre pueblo y parlamento que entre presidente del gobierno y un ministro o entre un alcalde y un concejal. Tampoco es idéntica la relación entre militantes y cúpula directiva de un partido que entre el jefe de dicho partido y alguno de sus asesores. Si las relaciones son distintas y también lo son los sujetos, parece razonable que las reglas reguladoras de la relación sean diferentes.

El funcionamiento de la corrupción política seguirá exactamente el mismo esquema diseñado por Gambetta con carácter general. Existirá corrupción política cuando $\mathrm{F}$ (político), que gestiona intereses como consecuencia de una relación de confianza (trust) reconducible al pueblo, directa $\left(\mathrm{T}_{1}\right)$ o indirectamente $\left(\mathrm{T}_{2-\mathrm{n}}\right)$, quebranta las normas de conducta establecidas por aquél $\left(\mathrm{a}_{\mathrm{r} 1}+\mathrm{a}_{\mathrm{w} 1}\right) \mathrm{O}$ por quién directamente le otorgara la confianza $\left(\mathrm{a}_{\mathrm{r} 2-\mathrm{n}}+\mathrm{a}_{\mathrm{w} 2-\mathrm{n}}\right)$ para obtener un

40 Tomamos la idea de cadenas de confianza de L. MOREL OCAÑA, El sistema de la confianza política en la Administración Pública, Madrid, 1994.

41 En este sentido muy claramente se pronuncian I. HOLLAND y J. FLEMING, "Advancing Ministerial Ethics" en el libro por ellos editado, y ya citado, Motivating Ministers to Marality, pág. 205. 
beneficio personal como consecuencia del precio $\left(\mathrm{M}^{*}\right)$ pagado por un tercero corruptor (C). La definición será también válida para la otra forma de hacer política en la moderna democracia, el partido político, con tan solo sustituir al pueblo como $\mathrm{T}_{1}$ por el conjunto de militantes. Por último, también será aplicable plenamente tanto el llamado "juego de apariencias" como los tipos especiales de corrupción apuntados en el apartado anterior.

Por ello, podemos aceptar la conclusión de Nieto cuando sostiene que al fin y al cabo la corrupción política no es mas que la culminación de la ruptura del vínculo de fidelidad que une a gobernante y gobernados ${ }^{42}$. Podemos, así, seguir tomando como referencia, aunque con matices, el modelo apuntado por Holmes ${ }^{43}$, y concluir que la corrupción política debe reunir cuatro caracteres básicos: a) La actividad ha de ser realizada por personas o grupos que ocupan un cargo público de naturaleza representativa por elección directa o por nombramiento indirecto. b) El cargo público ocupado ha de implicar el ejercicio de autoridad pública derivada y de un cierto margen de decisión libre en la gestión de los recursos transmitida. c) Entre las razones de la comisión del acto, u omisión, reputado como corrupto debe concurrir un interés personal del sujeto. Dicho interés puede ser directo o indirecto y debe implicar un beneficio personal otorgado por un tercero (u obtenido por sí mismo si es el beneficiario directo del acto sin intervención de un sujeto corruptor). d) El cargo público ha de ser consciente de que sus acciones y omisiones son o pueden ser consideradas contrarias a las reglas de comportamiento establecidas por los diversos sujetos que le han otorgado la confianza para acceder al cargo público por lo que tratará de mantener sus actos en secreto.

Así definida la corrupción política se nos sigue planteando un grave problema: la concreción de las normas reguladoras de la conducta del fiduciario. $\mathrm{O}$, en los términos de Malem, la determinación del marco normativo de referencia. Porque en toda la construcción del modelo la presencia, claridad y conocimiento de las reglas de conducta del agente ocupa una posición central. Esto es, señala gráficamente Gambetta ${ }^{44}$, dado que la corrupción depende de la existencia de claras reglas de conducta, si resulta que éstas son oscuras, cambiantes o controvertidas, nos podemos encontrar con que la definición se convierte en inaplicable. Ya hemos podido observar que la presencia de normas incompletas o indeterminadas es uno de los constantes problemas planteados a las diferentes formas de aproximación al concepto de corrupción política. Pero, además, en nuestro caso se tratará de normas, como se ha visto, cuyo contenido y alcance es variable según el eslabón en que nos encontremos dentro de la cadena de confianzas descrita más arriba. Determinar con

42 A. NIETO, Corrupción en la España democrática, citado, pág. 277.

43 L. HOLMES, "Corruption in Center and Eastern Europe", en el libro ya citado de BULL y NEWELL, Corruption in Contemporary Politics, pág. 193. Tomamos ya estas características como referencia en nuestro trabajo ya citado "Corrupción de los gobernantes, responsabilidad política y control parlamentario”, pág. 138-139.

44 Citado, pág. 50. 
claridad esas reglas o, al menos, establecer los criterios para que puedan ser determinadas en la práctica centrará el resto de las presentes reflexiones.

\section{BUSCANDO REGLAS DE CONDUCTA EN LA TEORÍA CONSTITUCIONAL: LA NOCIÓN DE TRUST}

La definición de las reglas de conducta que sujetan a los distintos titulares de la confianza ciudadana (directa o indirecta) para la gestión de los intereses comunes debe realizarse, en la perspectiva adoptada en estas páginas, desde la Teoría Constitucional si ello es posible. En tal sentido ha de notarse que a lo largo de todo el texto hemos utilizado el término trust para definir las relaciones establecidas entre el agente y el principal. El uso del vocablo inglés no es casual. Trust no es exactamente lo mismo que confianza (confidence) pues incorpora una serie de matices no presentes en el segundo término. En particular si lo analizamos desde la Teoría constitucional clásica.

Con carácter general Dunn ${ }^{45}$ y entre nosotros el profesor García López ${ }^{46}$ han estudiado con detenimiento la noción de trust y serán por tanto sus aportaciones las que seguimos en estas páginas. Quizás lo primero destacable es que el concepto procede del common Law en cuanto institución jurídico privada consistente en "un conjunto de bienes afectados por voluntad del sujeto constituyente a un fin. La persona en la que recae la administración del trust (trustee) es el único titular de las facultades inherentes a los derechos en él contenidos; su conducta (un deber de conciencia al servicio de la voluntad constituyente originaria) se mueve siempre en términos de gran libertad ${ }^{47}$. Los titulares de los bienes apenas tienen derechos sobre ellos y aparecen como simples beneficiarios. La posición del trustee se asienta en un "depósito

45 Sobre el tema con carácter general J. DUNN, The Political Thought of John Locke. An historical account of the argument of the "two treatises of Government", Cambridge University Press, primera edición, 1969 y en concreto sobre la noción de Trust en el pensamiento politico lockiano, del mismo autor, "The concept of "trust" in the politics of John Locke" en R. RORTY et al (eds), Philosophy in History, Cambridge University Press, primera edición, 1984. Para el papel de la idea de trust en los modelos principal-agente puede verse J. DUNN, "Trust and Political Agency", en F. GAMBETTA, Trust: Making and Breaking Cooperative Relations, Oxford, 1990, 73 y ss. Una derivación de estos planteamientos hacia la realidad actual en torno a la idea de accountability puede verse en J. DUNN, "Situating Democratic Political Accountability", en el conocido trabajo editado por A. PRZEWORSKI et al, Democracy, Accountability and Representation, Cambridge University Press, 1999, págs. 329 a 342. Sobre la vigencia histórica de la noción y su influencia, en particular, en el concepto moderno de responsabilidad política del Gabinete en la experiencia británica de la segunda mitad del siglo XVIII y principios del S XIX, puede consultarse D. BARANGER, Parlementarisme des origines: essai sur les conditions de formation d'un exécutif responsable en Angleterre, des années 1740 au début de l'âge victoreen, Presses Universitaires de France, París, 1999.

46 En su muy interesante "Estudio Preliminar" a la traducción española de W.G. HAMILTON, Lógica Parlamentaria, Congreso de los Diputados, Madrid, 1996. En concreto respecto a la noción examinada en el texto, págs. 161 a 182.

47 E. GARCÍA LÓPEZ, ibidem, págs. 165-166. 
de confianza" con un "correlativo deber de conciencia exigible ante los tribunales" que implica el respeto absoluto al cumplimiento de las reglas reguladoras del instituto. Reglas que van más allá del mundo jurídico, muy vinculadas a las ideas de lealtad hacia el principal o de buena fe en la gestión. El altísimo grado de libertad conferido para la gestión de los bienes afectos al trust viene compensado no sólo por la entidad de estos deberes, sino también por la intensidad de la rendición de cuentas del trustee ante el principal ya que asume «el terrible costo de sostener la defensa de la presunción de estar obrando permanentemente en justa correspondencia con la confianza por él recibida" de modo que si bien la confianza de la que dispone es muy amplia, se encuentra "contrapesada con importantes principios de desconfianza" "

Debe notarse, como apunta el profesor García, que aun pareciéndose, esta institución no es la del fideicomiso diseñada en el Derecho Romano. Es un instituto propio del Common Law. Y como tal un instituto con poca elaboración teórica. Pero donde las relaciones trustee-cestui que trustent no son las mismas que las existentes entre mandante y mandatario procedentes del Derecho romano.

En la noción iusprivatista de trust se apoyarán primero Locke y después, de forma mucho más detallada y elaborada, Burke para construir los elementos esenciales de la forma británica de entender las relaciones entre representantes y representados. Serán las reglas del trust (convenientemente adaptadas) las que regulen las relaciones entre los ciudadanos y sus representantes en el marco del government by society o del representative government británico ${ }^{49}$, teniendo en cuenta que con ello se articula un sistema normativo compuesto por reglas jurídicas y políticas simultáneamente. Esto es, la idea de trust aplicada a la confianza política supondrá que «el representante está obligado en conciencia a operar al servicio de la pública opinión, ${ }^{50}$ y tendrá tres tipos de consecuencias prácticas esenciales.

En primer término, el representante deberá ser titular de una cierta virtud acreditada. Ello es una consecuencia lógica del amplio margen de libertad conferido para la gestión de los intereses comunes. Si la sociedad le está confiriendo un amplio margen de actuación ha de estar razonablemente segura de que actuará de forma leal buscando el beneficio colectivo y no el personal. En el planteamiento de origen esta virtud se vincula a la idea de ejemplaridad en la trayectoria personal y social del representante. Ello, probablemente, la conecta con la idea maquiavélica de virtud y se explica por la exigencia de unas ciertas "cualidades éticas" a quienes aspiran a ejercer de trustees como garantía de que son dignos de merecer la confianza social para gestionar intereses colectivos. No se trata ya de una ética procedente de la moral aristo-

48 Ibidem, pág. 167.

49 Sobre la transformación del concepto de trust a través de las construcciones teóricas de J. LOCKE y E. BURKE, véase E. GARCÍA LÓPEZ, ibidem, págs. 168 y ss. y los trabajos ya citados de J. DUNN.

50 E. GARCÍA LÓPEZ, ibidem, pág. 170. 
crática o religiosa, sino de un tipo de ética vinculado al ejercicio del poder en el marco del Gobierno Representativo y con ello a la idea de "desinterés por lo propio a favor de lo que es común, ${ }^{51}$.

En segundo término, el otorgamiento del trust a quién, a priori, parece digno de confianza no es una operación ingenua por parte del trustee. Al contrario, viene compensada por un evidente "principio de desconfianza" hacia quien ejerce el poder en su nombre. Principio que supone que es al representante al que corresponde en cada momento demostrar que es digno de tal confianza de modo que esta pueda seguir siendo renovada. En el fondo late una concepción negativa de todo ser humano porque incluso el hombre que es considerado digno de confianza por su virtud, por su ejemplar trayectoria social y personal a favor del bien común, no puede dejar de ser vigilado y ha de estar siempre en condiciones de poder demostrar que su comportamiento ha sido y sigue siendo virtuoso (en el sentido antedicho de anteponer los intereses colectivos a los intereses personales) pues las tentaciones del ejercicio del poder son muchas y variadas. Ello supone que en esta relación no se aplica el principio de "presunción de inocencia" tan querido al Estado de Derecho ${ }^{52}$. Más bien supone una "radical inversión" de éste pues el principio vigente respecto a los representantes es la dura aplicación de una "presunción de culpabilidad", obviamente no en sentido jurídico, sino en sentido político. Esto es, la traslación de la carga de la prueba de la «buena conducta" hacia el trustee que en todo momento deberá estar en condiciones de demostrar que sus actos han respetado los intereses de quién le confirió la confianza. Dura carga que, no conviene olvidarlo, asume voluntariamente en cuanto acepta concurrir a un puesto de naturaleza representativa ${ }^{53}$.

En tercer y último lugar ${ }^{54}$, las anteriores características dejarían el instituto en un mero catálogo de buenos propósitos si el trustee no se encontrara sometido a una obligación permanente de rendir cuentas (to give an account) de la gestión de los intereses comunes realizada, así como de la pervivencia de las virtudes que le encumbraron al puesto representativo. De este modo, sostuvo Birch, pueden identificarse Gobierno Responsable y Gobierno Representativo ${ }^{55}$ en el sentido, matizado por Manin, de constituir las dos caras de una misma moneda ${ }^{56}$. La obligación de rendir cuentas se articula institu-

51 Sobre esta vertiente de la noción, E. GARCÍA LÓPEZ, ibidem, pp 173 a 178, la cita textual corresponde a la pág. 177.

52 En el mismo sentido con mucha claridad A. NIETO, Corrupción en la España democrática, citado, pág. 85 .

53 E. GARCÍA LÓPEZ, ibidem, págs. 178-179.

54 De nuevo sobre el tema E. GARCÍA LÓPEZ, ibidem, págs. 180-181.

55 A.H. BIRCH, Representative and Responsible Government, An Essay on the British Constitution, Toronto, 1969, también claramente destacada por C.J. FRIEDRICH, Constitución y Democracia, vol 2, Madrid, 1975, págs. 23 y ss.

56 Obviamente ya desde una perspectiva actual apunta MANIN cómo la idea de accountability es el componente democrático de la idea de representación. Véase B. MANIN, Los Principios del Gobierno Representativo, Madrid, 1998, pág. 286, aunque es una idea recurrente en toda la obra. 
cionalmente, en el planteamiento tradicional aquí resumido, ante las "organizaciones políticas permanentes" y de modo directo ante el Pueblo mediante el llamado juicio mediante la discusión y la formación libre de la opinión pública a través de la garantía de la libertad de expresión ${ }^{57} \mathrm{o}$ indirecto ante el Parlamento, mediante el principio de responsabilidad política como obligación gubernamental de rendición de cuentas (political accountability) ${ }^{58}$. Rendición de cuentas que puede culminar en la retirada del trust en los dos momentos más espectaculares del proceso: las elecciones periódicamente aseguradas para garantizar que efectivamente siempre se produzca tal rendición de cuentas y la eventual retirada parlamentaria de la confianza política al ejecutivo en su conjunto o a uno de sus miembros como consecuencia de la insatisfacción de la cámara ante el ejercicio del poder transmitido.

Así en el planteamiento de la Teoría Constitucional las reglas vinculadas al ejercicio del poder por parte de representantes tienen tres fuentes básicas: la virtud exigida al representante; el principio de desconfianza y la articulación de un sistema de rendición de cuentas. Resulta necesario que estas tres fuentes sean concretadas y actualizadas ahora ya desde la Realidad constitucional con el fin de establecer las reglas fundamentales reguladoras de la conducta de los políticos.

\section{LAS REGLAS DE CONDUCTA DE LOS POLÍTICOS DESDE LA REALIDAD CONSTITUCIONAL. UN ANÁLISIS DE LA EVOLUCIÓN EN EL REINO UNIDO}

La construcción de la noción de corrupción política a partir de un modelo agente-principal nos ha permitido utilizar el concepto clásico de trust en la teoría constitucional británica en los inicios del régimen parlamentario. De tal concepto es posible extraer con cierta claridad las fuentes básicas del sistema normativo de referencia aplicable a la actividad de los gobernantes en cuanto delegados de los ciudadanos para la gestión de los intereses colectivos. Sin embargo, tales fuentes han de pasar todavía por el tamiz de la Realidad Constitucional al menos en dos sentidos. Por una parte, es obvio que una construcción teórica procedente del siglo XVIII ha de ser debidamente actualizada. Por la otra, se trata de una construcción típica del modelo parlamentario de Westmister y de las especificidades del rule of Law británico muy diferentes de las condiciones en las que se articula el Estado de Derecho continental a cuya tradición pertenece la constitución española. Dedicaremos el presente apartado fundamentalmente a la primera de las cuestiones, para concluir este tra-

57 Sobre ambos conceptos de nuevo con carácter general, B. MANIN, Los principios del Gobierno Representativo, citado.

58 Sobre el la responsabilidad política como accountability, en castellano, R. BUSTOS GISBERT, La responsabilidad política del Gobierno, ¿realidad o ficción?, Madrid, 1998. 
bajo tratando de responder a la segunda (en la medida en que no se haya dado antes respuesta).

\section{V.1. ¿Reglas ÉTICAS DE CONDUCTA DE LOS POlíticos en la REALIDAD CONSTITUCIONAL?}

Parece razonable afirmar que la idea de "virtud" como comportamiento exigible a los gobernantes, sigue existiendo en nuestros modernos sistemas democráticos al menos en un sentido muy amplio. La competencia electoral se centra, en parte, en las virtudes que adornan a quienes aspiran a gobernar. El proceso electoral es parcialmente (aunque obviamente no sólo) un proceso de selección de "buenos tipos", en las palabras de Fearon".

Efectivamente, aún hoy, debemos afirmar que el comportamiento de los políticos respecto a su respeto a los estándares de conducta es importante. Así sostiene Jackson que todas las democracias occidentales exigen de sus gobernantes altos niveles de integridad ${ }^{60}$, puesto que en el fondo, a juicio de Malem ${ }^{61}$, se produce un notable impacto educativo, del comportamiento de los gobernantes sobre los ciudadanos. Así, sostiene Nieto «el deterioro de la probidad política de los políticos lleva consigo siempre un correlativo decremento de la probidad privada, puesto que los políticos — quieran o no- son el espejo que miran los ciudadanos, que siguen su ejemplo" ${ }^{62}$. Más claro aún será el Informe Nolan, que examinaremos más adelante, cuando afirma: «El pueblo tiene derecho a exigir unos muy altos estándares de comportamiento de los Ministros, en cuanto tiene un profunda influencia en la vida diaria de todos. Como Bogdanor nos dijo: desde los ministros deben fijarse los estándares de la vida pública, ${ }^{63}$. Esta idea de ejemplaridad de los gobernantes lejos de hacerse menos importante ha devenido particularmente esencial en las sociedades democráticas actuales como ha demostrado Gomá ${ }^{64}$. Efectivamente, los políticos se convierten en paradigmas sociales, en fuente de moralidad social. Y ello porque su posición procede de una relación de confianza que sólo

59 J.D. FEARON, "Electoral Accountability and the control of Politicians: selecting good types versus sanctioning poor performance", en A. PRZWEWORSKI, et al (editors), Democracy, Accountability and Representation, citado, págs. 55 a 97. 107.

60 R.J. JACKSON, "Honesty and corruption in the Canadian Federal Government”, citado, pág.

61 J.F. MÁLEM SEÑA, "Corrupción, racionalidad educación moral", en V. ZAPATERO (compilador), La corrupción, citado, págs. 181 y ss.

62 A. NIETO, Corrupción en la España democrática, citado, pág. 69.

63 Informe Nolan, Cap. 3, par. 4. First Report of the Comittee on Standards in Public Life, Cm. 2850-I, HMSO, Londres.

64 Véase con carácter general, J. GOMÁ, Ejemplaridad Pública, Taurus, Madrid, 2009, a quien seguimos en este punto de cerca. Sólo disentimos en el papel diferente que conferimos a la noción de trust frente a la noción de confidence explicado más arriba. El autor sostiene un punto de partida diferente (aunque no realmente contradictorio) en este punto, véase, la nota número 4, pág. 264. 
se confiere a quien sea considerado digno de ella, a quien sea capaz de inspirarla después de la realización de un juicio global sobre la persona. De este modo la idea de decorum en su comportamiento será clave en su relación con los gobernados, continúa Gomá, pues éstos no se fijan sólo en si «es un buen gestor, buen parlamentario, buen orador o buen comunicador, sino que, más allá de lo ceñidamente público, tomaremos en consideración qué clase de persona es - responsable, emancipada, fiable- y si se aproxima más o menos a esa imagen de ejemplaridad que tenemos en mente "65. En definitiva, la idea de ejemplaridad de los gobernantes será tanto más necesaria cuanto mayor sea la profundización en los valores democráticos en la medida en que suponen la sustitución de la decadente ejemplaridad por asentimiento por una pujante ejemplaridad por elección ${ }^{66}$.

El problema es determinar hoy qué elementos caracterizan a un candidato como un buen tipo o un tipo ejemplar de modo que sepamos qué tipo de comportamiento es el exigible. Es posible que en el momento de formulación del concepto de trust estuvieran claras tales reglas. Así lo apunta con claridad Weler respecto a los ministros ${ }^{67}$ : "hubo tiempos en el los que resultaba sencillo determinar el comportamiento adecuado para los ministros. Las normas de comportamiento se determinaban por los mismos principios que en un club masculino (...) eran lo que hacian los bombres decentes y bonorables (...). Esto puede que alguna vez haya funcionado (...). No había necesidad de escribirlo todo. Los que importaban sabían lo que debía hacerse. Los que no lo sabían, tampoco hacía falta que lo supieran. La vida política era cerrada y elitista". Estas palabras ponen de manifiesto el impacto que sobre las normas éticas de conducta de los políticos van a tener tanto la profundización en el principio democrático como la complejidad creciente del gobierno. Cuando el gobierno es cosa de élites extraordinariamente restringidas, la búsqueda de normas éticas es razonablemente sencilla en la moral común de la élite que, por otra parte, es muy eficaz en la exigencia de su cumplimiento. El problema se plantea cuando el gobierno es complejo y la participación se reconoce a todos los ciudadanos, pues la ética colectiva compartida desaparece y la eficacia en la exigibilidad de normas de conducta vinculadas a la ejemplaridad se hace impracticable. En tal sentido, concluye Gomá se trata de un inevitable efecto en las sociedades post-nihilistas y radicalmente igualitarias de nuestro tiempo. Efecto que, a su juicio, hace aún más necesaria la creación de esa cultura común de la ejemplaridad a partir del comportamiento social de los políticos electos ${ }^{68}$.

65 Ibidem, pág. 265.

66 Ibidem.

67 P. Weller, "Ministerial Codes, Cabinet Rules and the Power of Prime Ministres", en J. FLEMING \& I. HOLLAND, Motivating Ministers to Morality, citado, pág. 49.

68 J. GOMÁ, Ejemplaridad Pública, citado. Véase en general la construcción ya destacada del parágrafo 29, "Ejemplaridad electiva: los políticos", págs. 260-268 que aparece correctamente separada de la "Ejemplaridad estatutaria: funcionarios y corona" en el parágrafo 30 y último de la obra. 
Pero, aunque pudiéramos encontrar y determinar con claridad los mandatos normativos derivados de esa ética compartida socialmente, nos encontraríamos con el problema de que el político ocupa, señalan Fleming y Holland ${ }^{69}$, una posición ética única. Esto es, tanto por la entidad de sus poderes, como por su complejidad o por ocupar su puesto por una relación de confianza, lo cierto es que el político se enfrenta a dilemas en su comportamiento que sólo él y quienes ocupan puestos similares al suyo han de enfrentar. Y en la solución de tales dilemas únicos la hipotética moral social compartida no ofrecerá soluciones o, al menos, no serán en absoluto tan claras como sería deseable. Así no sólo creemos firmemente que no podemos encontrar reglas éticas de conducta socialmente compartidas en las sociedades actuales (en los términos de Gomá), sino que si éstas existieran probablemente no servirían para resolver los problemas de conducta únicos planteados en exclusiva a los políticos.

En definitiva, por tanto, las normas de conducta tradicionalmente vinculadas a la noción de trust devinieron inaplicables. Incluso, inexistentes porque no resultaba posible identificarlas. Y mientras no exista una ejemplaridad pública compartida a partir del comportamiento estable y continuado de los políticos como pretende incentivar Gomá (y, desde luego, de momento no existe) no tendremos parámetros para identificarlas.

Esta es precisamente una de las razones que, para Lord Nolan, justificaron la puesta en marcha en el Reino Unido del Comittee on Standards in Public Life que terminó aprobando el famoso Informe Nolan ${ }^{70}$ sobre estándares de conducta en la vida pública. En efecto, señala Lord Nolan ${ }^{71}$, que durante los años 90 se produce en el Reino Unido una crisis de confianza brutal en los políticos. Tal impopularidad derivaría, a su juicio, de los fallos y los abusos del poder y de la percepción social de la clase política basada en (1) una imagen de deshonestidad y de ser indignos de confianza; (2) mentirosos (económicos con la verdad), con una mala reputación por su falta de franqueza y (3) desleales respecto a la palabra dada en las campañas electorales ${ }^{72}$. Percepción que, por otra parte, acabaría reconociendo el Comité, tenía una importante justificación ante la comisión de abusos evidentes tanto a nivel par-

69 I. HOLLAND y J. FLEMING, "Advancing Ministerial Ethics", citado, págs. 205-206.

70 Committee on Standards in Public Life, First Report: Standards in Public Life, HC, Cmnd. 2850, 1995. Este informe ha sido traducido como Informe Nolan: Normas de conducta para la vida pública, Madrid, 1996. También hay comentarios a su contenido en nuestra doctrina, véase por todos J. GARCÍA ROCA, Cargos Públicos Representativos, Pamplona, 1999, págs. 130 y ss y la bibliografía allí citada. Los trabajos sobre el mismo en la doctrina británica son inabarcables.

71 The Right Hon. Lord NOLAN, "Motivating Ministres to morality", en el libro de idéntico nombre ya citado, págs. 11 y ss.

72 A ello se unirían cuatro factores magnificadores ante la opinión pública: el papel de los medios de comunicación en el que las "malas noticias se venden mejor", la carencia de perspectiva en el examen de los escándalos (el periodismo es un arte efímero); los políticos viven hoy en una pecera por lo que todos sus actos, hasta los más íntimos, son objeto de escrutinio público y, por último, la cuota de responsabilidad ciudadana más interesada en las malas noticias que en las verdades aburridas. Ibidem, pág. 12. 
lamentario como ministerial, la presencia de claras colisiones de intereses y un fuerte clientelismo (incluso nepotismo) asentado tanto a nivel parlamentario como gubernamental.

El trabajo del Comité concluyó, en una primera fase ${ }^{73}$, con el citado informe Nolan. Por una parte, se emprendieron las reformas legislativas pertinentes para afrontar las disfuncionalidades en relación a conductas corruptas. En tal sentido se procedió a regular algunos de los conflictos de intereses de los miembros del ejecutivo, se aclararon conceptos respecto a la regulación de conductas corruptas en el seno de los ministerios y se incidió en incluir como delitos formas de corrupción que sin constituir sobornos supusieran la obtención de beneficios privados ${ }^{74}$.

Por otra parte, y más interesante para el objeto de estas páginas, se afrontó la tarea de búsqueda de un conjunto de reglas éticas aplicables a los gobernantes. Así, se formularon los famosos 7 principios de la Vida Pública que el propio informe define y que conviene recordar aquí.

Desinterés (selflessness): los titulares de cargos públicos deberán tomar las decisiones exclusivamente en términos de interés público. No deben tomar ninguna decisión para obtener beneficios financieros o materiales para sí mismos, su familia o sus amigos;

Integridad (Integrity): los titulares de cargos públicos no deben adquirir obligaciones financieras o de otro tipo con terceros o con organizaciones ajenas al Estado que puedan pretender influir en el desarrollo de sus funciones públicas;

Objetividad (Objectivity): en el desarrollo de sus funciones públicas, incluidos nombramientos, contratos o recomendaciones a terceros para premios y beneficios, los titulares de cargos públicos deben tomar sus decisiones basándose en el mérito personal;

Responsabilidad (accountability): los titulares de cargos públicos han de rendir cuentas de sus decisiones y actos ante los ciudadanos y deben someterse a cualquier investigación que pueda considerarse apropiada;

Transparencia (openess): los titulares de cargos públicos deben ser tan abiertos como sea posible respecto a los actos y decisiones adoptadas. Deben explicar las razones de sus actos y sólo ocultar información cuando esté claramente involucrado un interés público más relevante;

Honestidad (honesty): los titulares de cargos públicos tienen la obligación de declarar todo interés que pueda tener relación con sus deberes públicos y dar los pasos necesarios para resolver cualquier conflicto que pudiera plantearse de manera que se proteja el interés público;

73 Debe tenerse en cuenta que el comité sigue existiendo y produciendo informes de enorme interés sobre los diferentes aspectos o desarrollos de la cuestión. La producción de este comité, así como las respuestas gubernamentales a los sucesivos informes aprobados, es de gran interés pero no puede ser objeto de estudio en estas páginas. Baste apuntar su continuidad en el tiempo y la labor de monitorización de las reformas realizadas con motivo de sus anteriores propuestas.

74 Ibidem, pág. 15. 
Liderazgo (leadership): los titulares de cargos públicos deben promover y apoyar estos principios mediante su liderazgo y ejemplo.

Estas normas generales de conducta fueron posteriormente desarrolladas por diversos Códigos de Conducta de naturaleza ética (en todos los que se reproducen los citados 7 principios) y que, en general, son exigibles desde el propio órgano que los aprueba y al que pertenecen los afectados.

Así, se han aprobado los Códigos de Conducta para los miembros de la cámara de los Comunes (The Code of Conduct, approved by the House of Commons on 13 july 2005, editado junto a The Guide to the rules relating to the confuct of Members, approved by the House of Commons on 9 february 2009) $)^{75}$ y para la cámara de los Lores (House of Lords, Code of Conduct, adopted on Monday $2^{\text {nd }}$ July 2001, as amended on Tuesday, 24 th July 2001) ${ }^{76}$. Códigos que se consideran vinculantes para los miembros del parlamento y cuyo control corresponde, como probablemente no pueda ser de otra manera al propio parlamento.

Del mismo modo los códigos de conducta se han extendido al ejecutivo mediante la publicación, primero, de las Questions of Procedure for Ministers en la época del gobierno Major que posteriormente se han convertido en el Ministerial Code $e^{77}$ y en una serie de códigos dirigidos a regular el funcionamiento del ejecutivo ${ }^{78}$ :

El Ministerial Code es sin duda el texto que mas nos interesa. Establece la regulación básica del comportamiento de los miembros del gobierno. La vigilancia de su cumplimiento corresponde a la cabinet office si bien la responsabilidad de ejecutarlo reside en el Primer Ministro. De hecho desde el primer ministerial code aprobado en 1997 por el Primer Ministro John Major, cada primer ministro (Blair aprobó dos, uno al ocupar el cargo en 2001 y otro tras su primera reelección en 2005) ha aprobado su propio código de conducta pese a que los contenidos resultan tremendamente similares (con matices interesantes resultado de los prejuicios ideológicos de cada primer ministro). Básicamente, como rezaba el subtitulo del código hasta su última versión de 2007, consiste en un codigo de ética y de guia procedimental para los ministros ( $A$ Code of Ethics and procedural quidance for Ministers). Desde un punto de vista general la definición de los deberes de los miembros del gobierno es muy clara desde el comienzo del texto, pues el primer mi-

7553 abigarradas páginas que, por supuesto, se pueden consultar con toda facilidad en www.parliament.uk con sólo introducir en el buscador las palabras codes of conduct. El acceso directo al documento puede obtenerse en http://www.publications.parliament.uk/ $\mathrm{pa} / \mathrm{cm} / \mathrm{cmcode} . \mathrm{htm}$

76 Bastante menos detallado que el anterior, accesible por la misma vía sencilla. Para un acceso directo: http://www.publications.parliament.uk/pa/ld/ldcond/ldcond.htm

77 Sobre el tema debe consultarse el detallado trabajo de A. BARRER, Prime Ministers $\&$ the Rule Book, Politicos, Londres, 2000.

78 De nuevo ha de destacarse la enorme facilidad de acceso a esta información pues basta acudir a la pagina oficial del gobierno británico (http://www.cabinetoffice.gov.uk/) para encontrar una pestaña que bajo el título genérico "codes of conduct" nos lleva a todos los códigos vigentes. 
nistro destaca en el propio prólogo del mismo que lo que se pretende es "asegurar que mantengamos los más altos estándares [de comportamiento] que el pueblo británico tiene derecho a esperar de nosotros". En consonancia con ello el principio general del código es que "Se espera de los ministros de la corona que se comporten de manera que mantengan los más altos estándares de propiedad ${ }^{79}$. Su contenido (apartado 1.2) debe leerse en el contexto de la general obligación de respetar el Derecho, incluido el derecho internacional y las obligaciones de los tratados y de apoyar la Administración de Justicia y proteger la integridad de la vida pública, esperándose de ellos el respeto de los 7 principio de la vida pública ya expuestos. Pero, además, el Código fija una serie de obligaciones específicas de los ministros agrupadas en 10 subapartados: (a) mantener el principio de responsabilidad política solidaria, (b) rendir cuentas ante el Parlamento, (c) asegurar que no se mentirá al Parlamento, (d) ser transparentes ante el Parlamento, (e) garantízar que los funcionarios a su servicio actuarán de forma leal con el Parlamento cuando sean llamados, (f) prever que no surgirá ningún conflicto (ni siquiera aparentemente) entre sus obligaciones oficiales y sus intereses privados; (g) no aceptar ningún regalo que pueda ("o que pueda razonablemente parecer que") comprometer su decisión o que le coloque en una situación impropia; (h) separar su papel como ministro y como representante de una circunscripción electoral; (i) no usar recursos públicos para satisfacer intereses de partido; y (j) mantener la imparcialidad de los funcionarios públicos no debiendo pedirles nada contrario al Código de los Funcionarios públicos $^{80}$.

Estos principios deben ser respetados por los miembros del gobierno. Ellos, individualmente, valoran cómo actuar y rinden cuentas de sus actos ante el Parlamento y ante los ciudadanos. Pero es el primer ministro el juez último de los estándares de comportamiento esperados de un ministro y de determinar las consecuencias de una eventual ruptura de las reglas ${ }^{81}$.

Tras estos, y otros principios menores, el código regula a lo largo de sus 28 páginas diferentes aspectos clasificados en torno a la relación entre los Ministros y otros sujetos y materias sensibles. El código, pues, se divide en 8 grandes títulos: Ministros y Gobierno; Ministros y Nombramientos; Ministros y departamentos ministeriales; Ministros y sus circunscripciones e intereses del

79 Ministers of the Crown are expected to behave in a way that upholds the highest standards of propriety. "Propriety" aquí es un término casi intraducible al castellano. Implica actuar con decoro, de acuerdo a las convenciones sociales.

80 La comprensión de los apartados b-e será plena cuando se explique la evolución del principio de rendición de cuentas como elementos básico del concepto de trust manejado en el apartado 4.3 .

81 Parágrafo 1.5 «Ministers are personally responsible for deciding how to act and conduct themselves in the light of the Code and for justifying their actions and conduct to Parliament and the public. However, Ministers only remain in office for so long as they retain the confidence of the Prime Minster. He is the ultimate judge of the standards of behaviour expected of a Minister and the appropriate consequences of a breach of those standards" 
partido; Conflictos de interés de los ministros; Ministros y presentación de políticas gubernamentales; Ministros y Parlamento; viajes ministeriales.

El código ministerial es completado con el código de conducta dirigido a ámbitos más relacionados con la función pública como el código de funcionarios públicos (civil service code) y el código de conducta relativo a la dirección de la administración (civil service management code). Particularmente interesante resulta la regulación del código de conducta de los asesores ministeriales (special advisers) mediante un texto aprobado en 2007, aunque enmendado en 2009 (code of conduct for especial advisers).

Este bloque de normas de conducta viene acompañado por unas fuertes obligaciones de transparencia informativa gubernamental que en virtud la freedom of information act del año 2000 (si bien no entró en vigor hasta el año 2005) permite conocer on-line interesantes datos sobre el comportamiento gubernamental que complementa los estándares de conducta exigidos a los miembros del Gobierno británico ${ }^{82}$.

En definitiva, por tanto, la ausencia de normas éticas de conducta ha sido resuelta con un sistema de autorregulación de las obligaciones de los distintos titulares del ejercicio del poder público. En el conjunto de los códigos de conducta británicos pueden encontrarse con claridad cuáles son los parámetros de comportamiento esperados de Parlamentarios (comunes y lores); miembros del ejecutivo (en el amplísimo sentido que se da al término en el Reino Unido); e incluso asesores ministeriales. Las normas éticas de conducta están ya bastante claras. Son normas o autoacordadas por los miembros del propio órgano o establecidas por el Primer Ministro como transmisor del trust parlamentario hacia los miembros del gobierno y sus asesores. En nuestro esquema agente-principal las normas éticas componentes de $\mathrm{a}_{\mathrm{w}}+\mathrm{a}_{\mathrm{r}}$ están, ahora, razonablemente claras. O parafraseando los términos del conocido capítulo de Oliver, ya sabemos al menos dónde y cuáles son los parámetros éticos exigibles a los políticos ${ }^{83}$.

82 Así en el Public Information Scheme editado en la pagina web de la Cabinet Office, podemos encontrar información tan útil respecto al comportamiento ministerial como la relativa a la listas de viajes realizados por los ministros por un valor superior a 500 libras (incluyendo fechas, destino, propósito de la visita, forma del viaje, número de asesores y acompañantes y coste total de viaje y estancia), la lista de los regalos realizados por los ministros por valor superior a $140 \mathrm{Li}$ bras (incluyendo fecha, ministerio que lo realiza, persona o entidad que lo recibe y en concreto el tipo de regalo de que se trata), la lista de los regalos recibidos por valor superior a 140 libras (incluyendo quien lo recibe, quien lo realiza, en qué consiste el regalo, el valor estimado y el destino dado al mismo); la lista completa de asesores (con indicación del ministro al que asesoran y las franjas salariales en las que se encuentran sus diferentes remuneraciones).

83 Nos referimos al trabajo de D. OLIVER, "Ministerial Acoountablity: What and Where are the Parameters?" en V. BOGDANOR et al The Law, Politics and the Constitution. Essays in honour of Geoffrey Marshall, citado. 


\section{V.2. El respeto al Derecho como Regla básica de Determinación DE LA CONDUCTA DE LOS GOBERNANTES}

La idea de respeto al Derecho lejos de debilitarse se ha fortalecido a lo largo de la evolución del sistema representativo. Probablemente incluso este proceso de fortalecimiento ha sido paralelo al debilitamiento de la presencia de normas de conducta no jurídicas. Parece razonable que los vacíos normativos generados por la inaplicación de normas éticas de conducta de imposible identificación hayan generado una cierta huida hacia el Derecho que compense las lagunas descritas. Sin embargo, antes de entrar a valorar ese proceso conviene que determinemos mejor el papel del Derecho en la fijación de las normas de conducta de los políticos.

Como bien señala Garzón Valdés ${ }^{84}$, el sistema normativo de referencia cuando hablamos de corrupción política es el de ala democracia representativa institucionalizada en el Estado de Derecho". En el mismo sentido, Lord Nolan recuerda que el punto de partida para enfrentarse a problemas de corrupción ha de ser el Derecho Penal ${ }^{85}$. Efectivamente, es el Derecho el que compone esencialmente el contenido de las reglas que han de regir las conductas de los gobernantes en un Estado de Derecho. Es en el Derecho donde encontraremos la definición clara de las reglas que establecen qué acciones son correctas y cuáles son incorrectas. Reglas que en ocasiones, las más, son comunes a todos los ciudadanos y reglas que en otros supuestos se dirigen en exclusiva a los gobernantes. Reglas que establecen los parámetros de conducta mínimos exigibles a todos los ciudadanos (en el código penal las que merezcan el máximo desvalor social, pero también en las relaciones entre privados y con los poderes públicos) y específicamente dirigidas a los gobernantes (desde obligaciones de transparencia, hasta incompatibilidades pasando por la regulación de conflictos de intereses o la tipificación penal de conductas sólo realizables por determinados tipos de sujetos entre los que se encuentren los políticos). El Derecho es una fuente, si no la esencial, de las reglas de conducta de los políticos. Eso no tiene duda alguna. Ahora bien, no nos interesa aquí tanto el contenido de ese conjunto de reglas jurídicas conformadoras del sistema normativo de referencia (o que constituyen parte de los que más arriba hemos descrito como $a_{\mathrm{r}}+\mathrm{a}_{\mathrm{w}}$ ), cuanto la forma en que opera esta sujeción al Derecho en un marco actualizado de la relación de trust entre gobernantes y gobernados.

En tal sentido Seibe ${ }^{86}$ recuerda que el Estado constitucional de Derecho se asienta en la separación entre ejercicio del poder y las cualidades morales de quienes lo ostentan. La moral personal, la moral colectiva no son un ins-

84 "Acerca del concepto de corrupción", citado, págs. 64-65.

85 "Motivating Ministers to Morality", citado, págs. 14-15.

86 W. SEIBEL, "Institutional Weakness, Ethical Misjudgment: German Christian Democrats and the Kohl Scandal" en I. HOLLAND \& J. FLEMING, Motivating Ministers to Morality, citado, págs. $27-28$. 
trumento aceptable de control del ejercicio del poder en el Estado de Derecho. Son la Constitución y el Derecho las bases de nuestra confianza en que quienes desempeñan el poder del Estado no lo usarán inadecuadamente. En tal sentido concluye López Calera, que en todo estado Democrático de Derecho el gobernante está sometido a una moral mínima socialmente aceptada que es el Derecho; «la moralidad básica de la política es el principio de legalidad,, 87 .

El cumplimiento de los estándares de ética política por los representantes del orden político será fundamental como forma de generar confianza en el la Constitución y en el Estado de Derecho. Ahora bien, en el Estado de Derecho el corazón de todo estándar de ética política debe incluir el respeto a la Constitución y al Derecho. Los gobernantes deben respetar estas pautas de conducta, pero en virtud de su posición en cuanto representantes de la comunidad han de hacerlo de una forma cualificada. Deben, continúa el profesor alemán, "demostrar públicamente ese respeto". Ese sería el test básico al que someter a los políticos, no un test moral. Pueden ser egoístas, adúlteros o malas personas y sin embargo ser unos buenos políticos para salvaguardar honradamente los intereses de una comunidad a través del respeto al Derecho.

De este modo observamos que el gobernante en el Estado de Derecho ha de tener un determinado compromiso con el Derecho. El político democrático de un Estado de Derecho ha de defender de manera activa la vigencia del Derecho. $\mathrm{Y}$ ha de hacerlo en su actividad pública y en su actividad personal. Un gobernante no comprometido con la defensa del Estado de Derecho no es un buen gobernante. No sólo ha de cumplir las normas jurídicas. Ha de defenderlas y respetarlas escrupulosamente. Debe estar en condiciones de "demostrar públicamente ese respeton en cualquier momento. Es el propio político del Estado democrático y de Derecho el que acepta tácitamente estas reglas del juego cuando asume la confianza popular (directa o indirectamente). Y ese compromiso por tanto supone que podemos considerar vigente (si se quiere de una manera aún más acentuada que en su origen) la idea de que al gobernante, en cuanto fiduciario o trustee de la comunidad, mantiene una relación con el Derecho diferente que el resto de los ciudadanos. En cuanto tal está sometido de igual manera que los demás a sus reglas (con por ejemplo, vigencia de la presunción de inocencia). Pero en cuanto político está sometido a tipos especiales de reglas jurídicas (específicamente creadas para los gobernantes) y a una forma de enjuiciamiento de su comportamiento que, por ser política y no jurídica, no se asienta sobre los mismos parámetros. En definitiva esta sujeto a una forma específica de enjuiciar políticamente la adecuación entre su comportamiento y el Derecho asentada en el principio de culpabilidad. Esto es, asentada en la obligación personal de demostrar en cualquier momento el compromiso con la defensa y el respeto del Derecho. No es pues extraño que la toda obligación ética exigida a los miembros del gobierno lo sea

87 N. LÓPEZ CALERO, “Corrupción, ética y democracia. Nueve tesis sobre la corrupción política", en F.J. LAPORTA y S. ALVAREZ (Eds.), La corrupción política, citado, págs. 120-121. 
siempre en el contexto del estricto respeto al Derecho o que se declare formalmente el deber de todo parlamentario de defender el Derecho ${ }^{88}$.

En definitiva, el gobernante está sujeto al Derecho. Pero no del mismo modo que el resto de ciudadanos. Está cualificadamente sujeto al Derecho porque se trata de un gobernante que goza de la confianza democrática en un Estado de Derecho lo que genera un mayor compromiso con el Derecho. Ahora bien, esta cualificada obligación no es una obligación que altere su status jurídico. Deberá jurídicamente respetar el Derecho igual que el resto de ciudadanos. Pero, a ese respeto jurídico se unirá otro tipo de respeto, de naturaleza política, exigible a través de los instrumentos garantizadores del correcto ejercicio del cargo público. En particular a través de la obligación permanente de rendir cuentas de sus actos en la que deberá estar en condiciones de demostrar siempre su inocencia.

\section{V.3. RENDICIÓN DE CUENTAS EN LA REALIDAD CONSTITUCIONAL ACTUAL}

Resulta curioso contemplar la idea de rendición de cuentas en el gobierno representativo desde una perspectiva histórica. No es este el momento de hacerlo ${ }^{89}$, pero sí debemos apuntar algunos elementos esenciales que nos permitan avanzar en el hilo discursivo de este estudio. La idea de responsabilidad de los gobernantes como rendición de cuentas ante quienes les hubieran otorgado la confianza se encuentra en el propio origen del gobierno representativo. Vinculado a la idea de trust y a la de gobierno representativo se aplica primero en un modelo de doble confianza (regia y parlamentaria) y posteriormente a un sistema de confianza parlamentaria exclusiva. Sin embargo, las transformaciones del sistema durante los siglos XIX y XX llevan aparejadas el paso de la comprensión de la responsabilidad como rendición de cuentas (accountability) a su percepción como la posibilidad de cesar al gobernante como consecuencia de la pérdida de la confianza política otorgada (liability to lose office). Con ello se produce una traslación del acento en la idea de responsabilidad desde lo que constituía en origen su esencia (el proceso de rendición de cuentas con la correspondiente forma concreta de articulación del sistema representativo en una forma de gobierno parlamentaria) a lo que no era más que una de sus consecuencias, probablemente, más espectaculares (el cese del Primer ministro o de alguno de los miembros del gobierno). Ello lleva a la creación de una dicotomía entre, usando la muy conocida terminología de Rescigno ${ }^{90}$, la responsabilidad institucionalizada en cuanto jurídica-

88 Parágrafo 1.1 del Ministerial Code, y parágrafo 5 ("Members hace a duty to uphold the law") del código de conducta de la cámara de los comunes.

89 Ya lo hemos intentado en otro sitio, vid. R. BUSTOS GISBERT, La responsabilidad política del gobierno, citado.

90 En su muy influyente trabajo, G.U RESCIGNO, La Responsabilitá Politica, Giuffré, Milan, 1967. 
mente exigible (las distintas formas de demostrar, formalizadamente o no, la retirada de la confianza bien del Parlamento al Jefe del Ejecutivo, bien de éste a alguno de los miembros del Gobierno) y la responsabilidad política difusa (en cuanto forma de obtener los ceses gubernamentales como consecuencia de la actuación de formas no institucionalizadas de presión sobre el ejecutivo). De este modo la idea de rendición de cuentas se diluiría en la posibilidad de remoción del ejecutivo en un sistema parlamentario, el control del gobierno por el parlamento y el control del ejecutivo directamente por la opinión pública y por sus actores más relevantes.

En fin, en la realidad de nuestros días la forma más clara de entender la rendición de cuentas sería, aparentemente, como una malla de responsabilidades en el sentido expresado por Oliver ${ }^{91}$. Esto es, el gobernante rendiría cuentas de sus actos de formas muy variadas (jurídica, política y moralmente) ante sujetos extraordinariamente diversos (los tribunales, el parlamento, el jefe del ejecutivo, el partido, los medios de comunicación, la opinión pública, el electorado, los grupos de presión, las agrupaciones locales de su partido, su propia circunscripción, algunas instancias internacionales, etc) mediante los más variados mecanismos. De esta red o malla de responsabilidades uno de los hilos más débiles será siempre el control de los políticos por el Parlamento puesto que todo gobernante en la forma de gobierno parlamentaria puede estar razonablemente seguro de que la mayoría parlamentaria, articulada en torno a un partido bien ordenado, nunca pondrá en peligro a su propio ejecutivo.

En otro lugar nos hemos detenido en el efecto demoledor de esta separación de la rendición de cuentas en dos mecanismos diferenciados sobre el conjunto del sistema ${ }^{92}$, por lo que no tiene sentido repetir aquí argumentos ya expuestos. Baste apuntar que la crítica doctrinal ${ }^{13}$ a este estado de la cuestión, iniciada en 1956 con Finer, continuada entre muchos otros por Marshall, y culminada por Woodhouse vendría acompañada por una terrible constatación práctica con la publicación del informe $\mathrm{Scott}^{94}$ en 1996 donde con toda crudeza se mostraría la ineficacia de la noción de responsabilidad política en-

91 Véase D. OLIVER, "Ministerial Accountability: what and where are the parameters", en The Law, Politics and the Constitution. Essays in honour of Geoffrey Marshall, Oxford University Press, Oxford, 1999 y Constitutional Reform in the UK, Oxford University Press, 2003, págs. 47 y ss, especialmente 54-55.

92 La responsabilidad politica del Gobierno, citado, especialmente, págs. 27 a 35.

93 Dentro de una bibliografía muy abundante nos referimos a los trabajos de S.E. FINER, "The individual responsability of Ministers", en Public Administration, XXXIV, 1956; G. MARSHALL, Constitutional Conventions, the Rules and forms of Political Accountability, Oxford University Press, Oxford, 1986 y D. WOODHOUSE, Ministers and Parliament. Accountability in Theory and Practice, Oxford University Press, Oxford, 1994.

94 Report of the Inquiri into the Esport of Defence Equipement and Dual-use Goods to Iraq and Related Prosecutions, HC (1995-96), 115. Sobre este informe y sus consecuencias puede consultarse A. TOMKINS, The Constitution after Scott. Government Unwrapped, Oxford University Press, 1998 y los números monograficos de Parliamentary affairs (enero 1997) y Public Law (otoño, 1996), 
tendida sólo como la obligación de dimitir en caso de perder una votación en la cámara baja o por pérdida de la confianza del Primer Ministro, así como las tremendas disfuncionalidades susceptibles de generar ${ }^{95}$.

El informe Scott (unido al movimiento ya descrito de recuperación de la ética pública) provocó la reacción del Parlamento británico con una especie de movimiento de péndulo, de vuelta al concepto clásico. Por primera vez en su Historia, tras un largo y minucioso trabajo en el Public Service Committee, se aprueba mediante una resolución parlamentaria, un informe sobre la responsabilidad política ${ }^{96}$ que contiene una definición clara de ésta plenamente conectada con las previas resoluciones del citado informe Nolan.

En primer término se recuerda que "Los ministros tienen una obligación ante el Parlamento que consiste en asegurar que el Gobierno explica sus actos" (parágrafo 21) para concluir que "Los ministros debe al Parlamento una obligación fundamental de rendir cuentas. Esto tiene, básicamente, dos significados. En primer lugar, que el ejecutivo está obligado a una rendición de cuentas - proveer información completa y explicar sus acciones ante el Parlamento de modo que esté sujeto a un control democrático adecuado. Esta obligación es central para el correcto funcionamiento del Parlamento por lo que el aquél Ministro que haya sido descubierto engañando conscientemente al Parlamento debe dimitir.(...). En segundo lugar, la obligación ministerial de rendir cuentas ante el Parlamento significa que el ejecutivo es susceptible de ser hecho responsable: debe responder a las preocupaciones y críticas suscitadas en el Parlamento por sus acciones porque los Miembros del Parlamento son los representantes elegidos democráticamente por el Pueblo. (...). Un ministro debe comportarse, y dirigir el trabajo de su Departamento, de modo que sea capaz de asegurar que conserva la confianza de su propio partido y de la Cámara" (parágrafo 26).

El informe fue aceptado en sus líneas generales por el Gobierno ${ }^{97}$ por lo que una resolución fue aprobada por unanimidad por la Cámara de los Comunes el 20 de marzo de $1997^{98}$ :

95 En el caso del informe SCOTT el engaño permanente e intencionado (y a la postre sin sanción ni jurídica, ni política, y sólo parcialmente electoral pues la popularidad de Major estaba ya muy erosionada antes del informe) de sucesivos ministros y gobiernos británicos al Parlamento y a la opinión pública en un tema tan sensible como la exportación de armas y material susceptible de uso militar a Irak durante la guerra entre este país e Irán en plena vigencia de un embargo, públicamente apoyado por el gobierno, decretado por Naciones Unidas.

96 Public Service Committee, Ministerial Accountability and Responsibility, HC (1995-96), 313.

97 Government Response to the Report of the Public Service Committee on Ministerial Accountability and Responsibility, HC, 1996-97, 67. Buena parte de sus contenidos fueron progresivamente incorporados, como se ha visto, a los sucesivos Ministerial Codes.

98 Un día antes había sido aprobada una resolución muy similar en la cámara de los Lores. El texto fue resultado de un acuerdo con el ejecutivo que respetaba razonablemente el espíritu del informe y por ello fue apoyado unánimemente y sin debate. Respecto al valor jurídico de la resolución, se afirmó, en un debate anterior, sobre el mismo asunto (HC Deb. Vol 290. Col 293, 12 de febrero de 1997) que el Gobierno había sido avisado de que la resolución permanecerá a través de las diferentes legislaturas, hasta que la cámara desee volver sobre ella. 
En opinión de esta Cámara, los siguientes principios deben inspirar la conducta de los ministros de la Corona en sus relaciones con el Parlamento: 1. Los ministros tienen un deber ante el Parlamento de rendir cuentas, y de ser considerados responsables por las políticas, decisiones y acciones de sus departamentos y next steps agencies. 2. Es de gran importancia que los ministros den una información adecuada y verdadera al Parlamento, corrigiendo cualquier error inadvertido en la primera oportunidad. Se espera de los ministros que conscientemente engañen al Parlamento que presenten su dimisión ante el Primer Ministro. 3. Los ministros tienen que ser tan transparentes ante el Parlamento como sea posible, sólo pueden negarse a transmitir la información cuando su conocimiento fuera contrario al interés público. 4. La interpretación del interés público del parágrafo 3 será decidida de acuerdo con las Leyes, y el Codigo Gubernamental sobre el acceso a la información gubernamental (...) 5. Los ministros pedirán a los funcionarios, que comparezcan ante los comités parlamentarios en su nombre y bajo su dirección, que sean tan útiles como sea posible en la provisión de adecuada y verdadera información.

Como puede verse el informe (y las concordantes obligaciones ya expuestas en el Ministerial Code) recuerda claramente a las obligaciones del trustee tal y como han sido definidas en páginas precedentes. Los ministros (pero obviamente es extensible a todo aquél gobernante que ejerce el poder como consecuencia de una confianza derivada reconducible al pueblo) están obligados a rendir cuentas por su comportamiento ante quienes le confirieron la confianza (el parlamento y, por cierto, el partido) en el órgano deliberante y representativo que se la confiríó no ya a ellos, sino a quién les designó (el primer ministro). Esta forma de regular la responsabilidad por el ejercicio del cargo político contiene en sí misma una doble garantía frente al mal ejercicio del cargo, aunque de distinta naturaleza.

En primer término, constituye fundamentalmente una garantía procesal de buen comportamiento del gobernante. Procesal porque no fija en sí misma las normas de referencia que han de servir para juzgar el comportamiento. Tampoco fija las sanciones a la infracción de tales normas. Cuáles sean tales normas y sus eventuales sanciones dependen del contenido sustantivo que demos a las obligaciones derivadas de la relación de confianza que en esta resolución no se establecen en modo alguno (pero que están fijadas en los ya expuestos códigos de conducta). Lo que se establece es el procedimiento a través del cual se llevará a cabo la aplicación de tales normas de conducta exigibles. Se hará a través de un proceso de rendición de cuentas público ante el Parlamento y consistirá en un juicio político cuya sentencia será la permanencia o no de la relación de confianza. Obviamente no es un juicio jurídico. No se valora si se han infringido o no las leyes pues tal cosa deberá determinarse, en su caso, a través del correspondiente procedimiento judicial ante los tribunales. Se valora si políticamente el comportamiento del ministro es juzgado de manera suficientemente positiva como para mantener el apoyo de su partido y de la cámara. 
En segundo término, esta forma de entender la responsabilidad política nos confiere dos normas sustantivas básicas que han de componer las reglas de conducta de todo gobernante: el deber de transparencia y la interdicción de la mendacidad. En efecto la consecuencia de que el proceso de rendición de cuentas sea esencial al sistema representativo de gobierno (y en concreto que la responsabilidad política del gobierno ante el parlamento suponga la obligación de rendir cuentas de éste individual y colectivamente ante la cámara que le confiere la confianza) es que no hay forma más clara de infringirla que no transmitiendo la información completamente (full account) o mintiendo durante el proceso de rendición de cuentas. En ambos casos se hace imposible la rendición de cuentas lesionando la esencia misma de la idea de representación o trust. Por ello no es de extrañar que el único acto tipificado con claridad tanto en cuanto a la conducta como en cuanto a la sanción sea la mentira ante el Parlamento. La mentira no tiene perdón posible. La sanción es, con ese peculiar estilo británico, muy clara: se espera de los ministros "que conscientemente engañen al Parlamento que presenten su dimisión ante el Primer Ministro". El error en la rendición de cuentas es aceptable si es de buena fe. Y la buena fe se habrá de demostrar (de nuevo la presunción de culpabilidad tan típica del trust) porque se han de rectificar los errores "en la primera oportunidad en que sea posible".

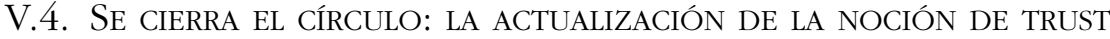 EN EL SISTEMA BRITÁNICO. REGLAS Y PROCEDIMIENTOS}

Para algunos ${ }^{99}$ el informe Nolan, el informe sobre responsabilidad política, los diferentes códigos de conducta y los mecanismos institucionales diseñados para hacerlos cumplir constituyen una nueva constitución del sistema parlamentario británico. Quizás no haya que llegar tan lejos. Pero, lo que si parece ser cierto es que se trata de textos de naturaleza constitucional, en la aún no escrita constitución británica, en la medida en que han producido una verdadera transformación de la realidad constitucional vigente hasta principios de los años 90 del pasado siglo. Desde nuestra perspectiva supone una actualización de la noción de trust en gran parte dirigida precisamente a prevenir y sancionar la corrupción política corrigiendo los defectos que tras más de dos siglos de evolución se habían dejado sentir en el Reino Unido. El esquema responde plenamente a la idea de trust original tal y como ha sido descrita por el profesor García.

Un conjunto de normas jurídicas y éticas que aseguren que los gobernantes defiendan el interés general. Esto es: (1) Un pleno establecimiento del sistema normativo de referencia que incluye las normas jurídicas (las genera-

99 Véanse distintas posiciones al respecto en D. WOODHOUSE, "The Role of Ministerial Responsibility in Motivating Ministers to Morality", en J. FLEMING \& I. HOLLAND, Motivating Ministers to Morality, citado, págs. 37 y ss. 
les y las específicamente dirigidas a los gobernantes) y las normas éticas establecidas para cada tipo de puesto ejercido; (2) Una sujeción cualificada al Derecho en cuanto gobernantes de un Estado de Derecho; (3) Mecanismos de rendición de cuentas ante quien de modo inmediato transmite la confianza, pero con referencia última ante el pueblo en cuanto ente del que ha de necesariamente proceder en última instancia el trust para el ejercicio del poder público.

Una última aclaración, ya anunciada en páginas anteriores, para tener una completa comprensión del sistema. El sistema normativo de referencia lo es de un determinado tipo de relación: la derivada de una relación de trust. No deriva del principio de imperio de la ley y de sujeción al Derecho. En el sistema normativo de referencia se incluyen normas jurídicas, pero no es un sistema normativo que responda a relaciones jurídicas en sentido estricto ni tiene por tanto los mismos instrumentos y procedimientos coactivos del Derecho. Está relacionado con el Derecho. Pero opera por separado.

En definitiva, el cumplimiento de las normas no es susceptible de un juicio jurídico. Es fruto de un juicio político realizado por los sucesivos sujetos transmisores del trust mediante un proceso de rendición de cuentas. Las sanciones girarán en torno al prestigio personal de cada gobernante afectado lo que, a su vez, condicionará de forma determinante su aptitud para seguir desempeñando un cargo (pudiendo llegar a obligarle a dimitir) o para optar en el futuro a otros puestos. No se tratará de imponer una pena o una sanción jurídica. No se tratará de establecer su inocencia o culpabilidad jurídica. No se realizará mediante un proceso judicial ante los tribunales. Se tratará de establecer su inocencia o culpabilidad política mediante un proceso político democrático realizado ante el partido, ante la opinión pública, ante el parlamento y, en su caso, ante el primer ministro imponiéndole una sanción política, cuya máxima pena será la no renovación del trust en su día otorgado.

De esta forma las normas jurídicas actúan de manera bifronte: como parámetro de juicio del gobernante en el mundo jurídico, pero también como parámetro de juicio en el mundo político. En el primero existe un deber de respeto. En el segundo un deber de apoyo expreso. En el primero el derecho a la presunción de inocencia es irrenunciable. En el segundo la presunción de culpabilidad es consustancial a la confianza otorgada. Son dos tipos de responsabilidad, la jurídica y la política, que deben seguir separadas ${ }^{100}$.

100 Nos hemos ocupado con detenimiento de esta diferencia en la actualidad en "Responsabilidad Política y Responsabilidad Penal", en Jueces para la Democracia, 60, Noviembre, 2007, pág. 56 y ss. 


\section{REFLEXIONES DESDE LA REALIDAD CONSTITUCIONAL ESPAÑOLA}

Hasta aquí el intento de esclarecer el concepto de corrupción política desde una óptica jurídico-constitucional. La corrupción política es la traición, normalmente mantenida en secreto, del trust popular otorgado (directa o indirectamente) a los gobernantes mediante la ruptura de las reglas reguladoras de esa relación debido al interés de obtener un beneficio otorgado por un tercero. Tales reglas incluyen un conjunto heterogéneo de normas (jurídicas y éticas) que es imposible identíficar con claridad desde una óptica constitucional pero que pueden concretarse mediante la adopción de textos de naturaleza cuasiconstitucional. Las normas de conducta de los gobernantes de naturaleza jurídica no son sólo parámetros derivados del Estado de Derecho, sino que, como consecuencia de la legitimidad democrática de los gobernantes, sirven de parámetro político de juicio de aquellos no en cuanto a su cumplimiento estricto (objeto del pertinente proceso judicial), sino en cuanto a su respeto cualificado. El proceso para enfrentarse a la corrupción política es el proceso de rendición de cuentas que actúa de forma preventiva y represiva. Cualquier obstaculización a este proceso mediante el ocultamiento de información o la mentira son por ello (por definición) la peor de las acciones de un gobernante. Cuando además la corrupción política implica quebrantamiento de normas jurídicas puede producirse una sanción penal. Pero el que ésta no se produzca no significa que no haya corrupción política. El control penal de la corrupción política es, sostiene Andrés Ibáñez ${ }^{101}$ un control de última instancia, para las degradaciones criminales de la política. La ausencia de sanción penal por tanto significa que el comportamiento desleal respecto a las normas de conducta establecidas para los gobernantes no merece el desvalor penal, o simplemente que no se ha podido demostrar en un juicio ${ }^{102}$. Dicho en términos rotundos: mentir al parlamento para justificar los propios actos nunca será un delito de corrupción (es posible que hasta sea un derecho derivado del derecho a no declarar contra sí mismo), pero sí será corrupción política si con ello se pretende ocultar razones de los propios actos que impliquen la obtención de beneficios personales.

Estas conclusiones son, a mi juicio, válidas con independencia del Estado o la forma de gobierno en la que nos encontremos. El modelo británico tomado como referencia sería un ejemplo muy ilustrativo en cuanto ha procedido a una buena identificación del sistema normativo de referencia y ha recuperado el contenido mínimo de la responsabilidad como rendición de

101 P. ANDRÉS IBÁNEZ, "introducción" en el trabajo por el coordinado, Corrupción y Estado de Derecho. El papel de la jurisdicción, citado, pág. 14., destacado también por el mismo autor en "La corrupción en el banquillo. Jurisdicción penal y crisis del Estado de Derecho" en F.J. LAPORTA y S. ALVAREZ (eds), La corrupción política, citado, págs.225-226.

102 En el mismo sentido véase, A. NIETO, Corrupción en la España democrática, citado págs. 73 y ss. 
cuentas $^{103}$. Pero no podemos acabar sin hacer una referencia a la Realidad Constitucional española.

España no es el Reino Unido, ni el modelo parlamentario español es el modelo de Westmister. No pueden trasladarse las soluciones sin más. En especial cuando las diferencias son tan profundas como las existentes entre la organización constitucional del poder británica y la continental, en general, y la española en particular ${ }^{104}$. Sin embargo, si algo demuestra la realidad española de los últimos años es que las normas de conducta de los gobernantes no están claramente identificadas y que la responsabilidad política de los gobernantes no se mide en términos de rendición de cuentas sino en puros términos de apoyo numérico a la confianza de un gobernante. El debilitamiento de ambos pilares ha producido el excesivo fortalecimiento del Derecho como único parámetro de conducta de los gobernantes. Un Derecho entendido no desde el principio de la desconfianza típico de la teoría constitucional clásica, sino desde un politicamente irreal principio absoluto de igualdad ante la ley. La identificación entre responsabilidad política y responsabilidad penal, la continua alegación de la presunción de inocencia penal de gobernantes implicados en procesos judiciales elimina de un plumazo la idea de que sólo debe ser gobernante de un Estado democrático aquél que sea digno de la confianza ciudadana como consecuencia de la ejemplaridad de su comportamiento, aquél que sea un buen tipo. Al realizar esa identificación nuestra realidad constitucional está confiriendo carta de naturaleza a la aberrante conclusión de que para ser considerado un buen tipo, para ser considerado digno de confianza, basta con que no haya sido condenados penalmente. En fin, a día de hoy el código de conducta de un gobernante español es el código penal (con todas sus garantías procesales). Esto es, el texto que contiene los comportamientos que merecen el máximo desvalor para una determinada sociedad.

Urge pues en la realidad constitucional española que cuanto antes se proceda a una definición de las reglas de conducta exigibles a los políticos que permita evaluar el grado de cumplimiento de las expectativas de comportamiento presentes en la sociedad española. Y de la experiencia británica pue-

103 Avalado por la exportación del modelo en particular a aquellos Estados que más claramente siguen el modelo de Westmister como Australia o Canadá y a sus subdivisiones territoriales. Al respecto pueden verse los diferentes trabajos de Weller o Wanna \& Gash (respecto a Australia), Shephard (respecto a Escocia), Jackson (Canadá), Preston (Queensland), Fleming (Nueva Gales del Sur) incluidos en Motivating Minsiters to Morality.. Pero no debemos tampoco deslumbrarnos, el sistema diseñado tiene fuertes críticos y puntos débiles que no han sido objeto de estudio en estas páginas y que son adecuadamente descritos en los trabajos recién citados. Igualmente no podemos evaluar el grado de eficacia que ha tenido dada la persistencia de escándalos en la vida pública británica.

104 Por solo citar la más evidente, buena parte de las normas de conducta mencionadas en los apartados anteriores son en el caso español absolutamente innecesarias por estar plenamente reguladas en las diversas ramas del Derecho administrativo no ya como normas éticas sino como auténticas normas jurídicas exigibles directamente ante los tribunales (esto es, con una eficacia superior a sus correlativas normas deontológicas británicas). 
den, creo, aprenderse algunas lecciones útiles. Baste aquí destacar, casi como conclusiones, sólo algunas:

Los códigos de conducta pueden ser una buena forma de afrontar (no de solucionar pues la solución total no es posible y la eficacia de las medidas depende de muchos otros factores no examinados en el texto) la corrupción política porque pueden servir para definir con claridad las normas de ejemplaridad asumidas por los gobernantes. Esto es, pueden completar correctamente, desde la obligación o exigibilidad política derivada del proceso de rendición de cuentas consustancial al sistema representativo, el conjunto de reglas aplicables a los gobernantes. Con ello no se pretende, ni mucho menos, sustituir a las normas jurídicas (penales y administrativas) reguladoras de la cuestión. Se pretende completarlas y establecer la cualificada vinculación del gobernante hacia su cumplimiento. Ahora bien, avisan Fleming y Holland, un sistema de códigos de conducta mal diseñado o mal aplicado puede "tener la capacidad de exacerbar el problema" ${ }^{105}$.

La elaboración de las normas de conducta de los gobernantes no debe hacerse a golpe de escándalo ${ }^{106}$. Parece ser una regla universal (a la que España no es ajena) que las medidas anticorrupción o de motivación de la moralidad de los políticos sean la consecuencia inmediata de un escándalo con amplio eco en los medios de comunicación o de una campaña electoral de regeneración de la vida pública. No es ese el mejor escenario pues esta forma de actuar da lugar a compromisos confusos ${ }^{107}$. Es bien cierto que los escándalos son catalizadores de la adopción de medidas contra la corrupción, pero no han de tener como objetivo encontrar a los concretos culpables de un determinado caso ya que "encontrar culpables no es tan importante como encontrar medios de limitar comportamientos inadecuados "108. Una estrategia de este tipo implica la creación de normas ad hoc y no un tratamiento sistemático de la cuestión. Por otra parte, la fatiga ética que rápidamente aqueja a todos los gobernantes ${ }^{109}$ que actúan en este contexto suele impedir una mínima continuidad y coherencia de las medidas adoptadas. El modelo británico es toda una lección de cómo hacer las cosas desde el consenso general, la lentitud, la evaluación permanente de las medidas adoptadas y su constante mejora. En particular la formulación parlamentaria y consensuada de los principios éticos de la vida pública como principios generales y después el

105 J.FLEMING \& I. HOLLAND, "The case for Ministerial Ethics" en el libro por ellos editado, Motivating Ministers to Morality, citado, pág. 8.

106 Corrupción política y escándalo político no son, ni mucho menos, lo mismo. Vid al respecto F.J. MALEM SEÑA, "El fenómeno de la corrupción”, citado, págs. 84-87.

107 R.J. JACKSON, "Honesty and corruption in the Canadian Federal Government", citado, pág. 107. La expression "messy compromises" procede de Isaiah Berlin.

108 R.J. JACKSON, ibidem, pág. 110.

109 Con estos términos se refieren los autores recién citados a que "es relativamente sencillo que un gobierno introduzca estándares de conducta al ser elegido, porque usan tal cosa como un medio de establecer un contraste entre ellos y la previa, inevitablemente, administración corrupta. Pero, según pasa el tiempo desarrollan un sentimiento de ser perseguidos injustamente", J.FLEMING \& I. HOLLAND, "Advancing Ministerial Ethics", ibidem, pág. 205. 
desarrollo de estos principios en cada uno de los órganos en los que se articulan la cadena de confianza necesaria para ocupar un cargo público parece la única vía razonable.

En la elaboración de los códigos de conducta debe diferenciarse los distintos lugares en los que se produce la transferencia de confianza (partido, parlamento, ejecutivo, municipios) porque las posiciones éticas de los políticos son no solo únicas respecto a los ciudadanos, sino también únicas entre sí. De alguna manera en cada caso el Código de Conducta debe ser, señala Lord Nolan, "la expresión escrita del ethos de la organización". Es singularmente importante la regulación de códigos de conducta razonablemente eficaces en el seno de los partidos porque se trata de instrumentos básicos de la democracia y, simultáneamente, fuente de buena parte de los actos de corrupción política ${ }^{110}$.

Si el código de conducta debe expresar el ethos de la organización debe tratarse de autorregulaciones. Establecidas por los propios afectados, tras un diálogo público entre todos los actores en el que se fijen los elementos esenciales del mismo y no el resultado de la derivación de una serie de principios éticos generales formulados por una determinada y concreta ética ${ }^{111}$. Han, pues, de ser fijados por el parlamento, por el partido, por el jefe del ejecutivo respecto a todos los miembros del gobierno, etc. A diferencia del caso británico (en el que el objeto de regulación es no sólo el comportamiento ético, sino también los procedimientos de actuación que en España están plenamente regulados por el Derecho administrativo) estos códigos de conducta serán una suerte de compromiso ético asumido en los distintos ámbitos en los que se desarrolla el sistema representativo. Compromiso que implica el deber político de cumplirlo y que utiliza como mecanismo de cumplimiento el proceso de rendición de cuentas cuyo último juez será siempre el cuerpo electoral.

Para que los Códigos de conducta gubernamental puedan cumplir su función de dotar de contenido al sistema normativo de referencia de todo gobernante, han de ser claros y accesibles ${ }^{112}$. Pero no necesariamente continuos

110 Así, señalan los autores recién citados, que los códigos de conducta partitocráticos deben hacer compatible la tensión evidente entre su carácter cuasi público de instrumentos de la democracia con la lógica interna de funcionamiento como asociaciones privadas. Ibidem, págs. 209210.

111 R.J. JACKSON, "Honesty and corruption in the Canadian Federal Government", citado, pág. 117.

112 Sobre la importancia de la publicidad y el salto cualitativo que supone la eliminación del "velo de secreto" que envolvía a las normas de conducta interna en los gobiernos británico y australiano, véase P. WELLER, "Ministerial Codes, Cabinet Rules and the Power of Prime Minister", citado, págs. 66 y ss. No podemos resistirnos a comparar la enorme facilidad para encontrar los códigos de conducta británicos con la imposibilidad manifiesta de encontrar los códigos que se supone rigen los partidos políticos en España o los de algunos gobierno autonómicos (como el anunciado código del gobierno balear se supone que aprobado en diciembre de 2009 que no hemos sido capaces de encontrar en ninguna página web ni oficial ni extraoficial). Algo parecido ocurre con el códígo de conducta gubernamental que para encontrarlo hay que acudir al BOE concreto en que fue publicado ( 7 de marzo de 2005) pues no aparece en ninguna página ni en ningún buscador de los cientos de páginas web del Gobierno. 
en el tiempo. Los compromisos de comportamiento pueden y deben cambiar a lo largo del tiempo. Cada presidente del gobierno determinará unas prioridades éticas acordes con su propia capacidad de dirección de un ejecutivo; los compromisos asumibles dependerán del contexto político en que se enmarquen (no será lo mismo el código ético de un gobierno monocolor que de un gobierno de coalición) o simplemente podrán reflejar opciones ideológicas diferentes.

Su exigibilidad no ha de ser jurídica, sino política. El proceso de $a c$ countability es el que determina al final el grado de culpabilidad de cada actor. No conviene confundir el plano del cumplimiento de las normas de conducta de los gobernantes con el del cumplimiento de las normas jurídicas. Este tiene gran importancia en aquél pero no es, ni mucho menos, lo mismo.

El contenido puede ser enormemente variable. Probablemente mucho más reducidos que los códigos de conducta de los Estados del modelo británico. Pero, necesariamente hay dos normas que han de contener: el deber de transparencia y la prohibición de mendacidad. Y ello porque son precondiciones de todo el modelo diseñado.

Es evidente que ninguno de los códigos de conducta aprobados en los últimos años en nuestro país cumple mínimamente las condiciones descritas. En unos casos se trata de puro marketing político como consecuencia de escándalos particularmente graves. En otros aunque existiera una clara intención de cambio, la fatiga ética se apoderó rápidamente de los órganos impulsores $^{113}$. El que se alcance alguna solución del tipo defendido en estas páginas dependerá de la propia voluntad de los actores políticos que, precisamente, son los máximos beneficiarios de que no existan normas adicionales que sujeten su comportamiento. Sin embargo, cualquier estrategia anticorrupción requiere, recuerda Garzón Valdés, "la adhesión interna al sistema democrático por parte de sus decisores" ${ }^{114}$ por lo que son los citados actores los que no deben olvidar que la ausencia de tales normas provoca una lenta pero constante erosión de la propia confianza ciudadana en el sistema. Las pequeñas corrupciones que no encuentran normas de conducta prohibitivas (los pequeños -y no tan pequeños - regalos o comisiones, el clientelismo no demostrable, los viajes no contabilizados, las optimizaciones tributarias, las permanentes irregularidades contables de los partidos, etc) o las grandes corrupciones no demostradas penalmente y que pese a la convicción política de su existencia no llevan a aparejado ninguna valoración política negativa (declaraciones

113 Tales serían las medidas del primer Gobierno de Rodríguez Zapatero aprobando un código ético gubernamental (que, por otra parte no resiste comparación con el británico) o normativa específica de conflicto de intereses que no ha sido examinada en el texto, o el Código ético asumido por el Partido Popular de Aznar en 1993 y recientemente reformulado tras diversos escándalos. Saludamos en su día las citadas medidas del primer gobierno de Rodríguez Zapatero como "esperanzadoras, pero con un largo camino por delante" (Corrupción de los gobernantes, responsabilidad política y control parlamentario", citado, págs. 153 y ss) en 2005. Desgraciadamente el largo camino no ha sido recorrido ni en la teoría ni en la práctica.

114 E. GARZÓN VALDÉS, "Acerca del concepto de corrupción", citado, pág. 64. 
de intereses falsas; financiación ilegal de partidos políticos, etc) unido a un clima de absoluta falta de respeto a las más mínimas obligaciones de transparencia y de sinceridad en las declaraciones públicas acaban minando al propio sistema democrático. Y cuando la corrupción política se hace sistémica lo que estará en juego será la propia supervivencia de un Estado que verdaderamente pueda llamarse democrático. Cuando la virtud civica no es respetada por quienes tienen el máximo deber de ejemplaridad en una sociedad democrática (postnihilista e igualitaria) ${ }^{115}$ no se puede esperar que sea valorada (y, sobre todo, exigida democráticamente) por los ciudadanos. El, en los términos ya citados de Malem, impacto educativo, del comportamiento de los gobernantes sobre los ciudadanos es demasiado importante para ser ignorado. Los ejemplos están demasiado cerca y son terriblemente claros. Desde la propia realidad constitucional española y desde los principales actores políticos españoles la opción debería estar razonablemente clara. Entre el intento de recuperación de valores cívicos en la vida pública del Reino Unido de Lord Nolan y la corrupta (en el sentido maquiavélico tan bien descrito en este mismo número por Eloy García) Italia de Berlusconi deberíamos tener claro cuál es el camino a seguir.

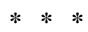

TitLe: Political corruption: a study from constitutional theory and practice.

ABSTRACT: This article looks for a concept of political corruption useful for a constitutional analysis from a legal point of view. Firstly the different options used in the literature to analyze the concept are classified. A principal-agent model is chosen as the best option. One main problem in this model is the establishment of the concrete rules governing the relationship between agent and principal and the normative system which determines, partially, the presence of a politically corrupt action. Those rules are defined from the classical Constitutional theory applying the concept of trust as a far more complex notion than that of political confidence. This concept presupposes the existence of some ethical rules for politicians in charge of public offices, the presence of a qualified duty to uphold Law and a permanent process of political accountability. The classic notion is then analysed from the Constitutional Reality perspective in the rich experience of the United Kingdom since the last decade of the XXth century. Especially after the passage of the Nolan Report, the new codes of conduct and the reformulation of the ministerial responsibility doctrine. Such a Constitutional Reality cannot be extrapolated to Spain so the article finishes with some guidelines to improve the identification of the conduct rules that, in last instance, will establish the existence of political corruption

RESUMEN: Este trabajo busca un concepto de corrupción política útil para su análisis desde el Derecho Constitucional. Para ello se clasifican las diferentes formas de estudio del concepto de corrupción politica optando por un modelo agente-principal. Este modelo plantea el problema de determinar las normas reguladoras de la conducta del agente impuestas por el principal y con ello del sistema normativo de referencia que determina, parcialmente, la presencia de una conducta políticamente corrupta. La determinación de estas normas se hace primero desde la Teoría Constitucional. Para ello se aplica al concepto la noción de trust entendida como una relación más elaborada que la de confianza política. Esta noción presupone la existencia de una serie de normas

115 J. GOMÁ, Ejemplaridad pública, citado. 
de conducta éticas para los gobernantes, la exigibilidad de una actitud cualificada hacia el Derecho y la presencia de un proceso constante de rendición de cuentas. La noción clásica de trust es actualizada tomando como referencia la rica experiencia británica sobre la cuestión desde la última década del siglo XX, en particular, como consecuencia de la aprobación del Informe Nolan, los nuevos códigos de conducta y la reformulación de la doctrina de la responsabilidad política. Tal Realidad Constitucional no es aplicable a España por lo que el trabajo termina estableciendo criterios para mejorar la posibilidad de identificar las reglas de conducta exigibles a un gobernante que en última instancia serán las que determinen la existencia o no de corrupción política.

Keywords: Political Corruption. Principal-Agent Analysis. Political codes of conduct. Rule of Law and Political Accounlability.

Palabras clave: Corrupción Política. Análisis principal-agente. Códigos de conducta política. Estado de Derecho. Responsabilidad política. 